ISSN: 0514-7336 — ISSN electrónico: 2386-3943

DOI: https://doi.org/10.14201/zephyrus202085163184

\title{
PRIMEROS AVANCES DE LA INTERVENCIÓN ARQUEOLÓGICA EN LOS MAUSOLEOS DE LA PUERTA SURESTE DE BAELO CLAUDIA: EL MONUMENTO DE IUNIA RUFINA
}

\section{First advances of the archaeological excavation in the mausoleums of the southeastern gate of Baelo Claudia: the monument of Iunia Rufina}

\author{
Fernando Prados Martínez*, Helena Jiménez Vialás** y Lorenzo Abad Casal* \\ * Instituto Universitario de Investigación en Arqueología y Patrimonio Histórico. Univ. de Alicante. Campus de \\ San Vicente del Raspeig.03690 Alicante.Correo-e: fernando.prados@ua.es; lorenzo.abad@ua.es. ID ORCID: https:// \\ orcid.org/0000-0001-8441-8508; https://orcid.org/0000-0002-5468-4837 \\ ** Dpto. de Prehistoria, Arqueología, Historia Antigua, Historia Medieval y CC. y TT. HH. Facultad de Letras. Univ. \\ de Murcia. Campus de la Merced. 30001 Murcia. Correo-e: vialas@um.es. ID ORCID https:/lorcid.org/0000-0002- \\ 9679-6968
}

Recepción: 4/12/2019; Revisión: 11/02/2020; Aceptación: 16/03/2020

Resumen: En este artículo se presenta la excavación arqueológica desarrollada en los mausoleos emplazados junto a la puerta sureste de la ciudad de Baelo Claudia (Bolonia, Tarifa, Cádiz). De estos dos monumentos apenas quedaba rastro en superficie. Dicha intervención trataba de aportar luz sobre su estructura, sobre su posición respecto al decumanus y sobre su cronología. Para ello se realizó una excavación en área abierta en la que se pudo constatar que habían padecido un expolio ya en época antigua y sufrido las consecuencias de un terremoto. Este evento sísmico había derrumbado los edificios cubriéndolos de escombros, sellando muchos de sus elementos decorativos. La excavación, por tanto, ha permitido recuperar estos elementos en buen estado de conservación, sobre todo de uno de los dos mausoleos. De los hallazgos destacan los órdenes arquitectónicos completos que fueron ejecutados en mármol, así como el epígrafe funerario, realizado con letras de bronce. Se trata de un importante hallazgo tanto por la calidad de la decoración arquitectónica, como por el hecho de que se trata de una de las escasas inscripciones realizadas en litterae aureae conservadas en el occidente del imperio.

Palabras clave: Necrópolis; decumanus; mausoleo; orden corintio; inscripción; litterae aureae; terremoto.

AвSTRACT: Recent archaeological works in the mausoleums near the South Eastern Gate of Roman Baelo Claudia (Bolonia, Tarifa, Cádiz) are presented in this paper. Both monuments were partly visible before the excavation and our aim was to throw light on their structure, spatial relation to the decumanus and their chronology. The open-area excavation allowed us to determine that they were looted in ancient times and that they even suffered an earthquake. Fortunately, the collapse of the mausoleums caused by that seismic episode covered -and hid- the different decorative elements with debris. Thus, the excavation has allowed recovering these valuable elements from one of the two mausoleums: the complete architectural order made in marble (base, column and capital), as well as the funerary inscription, made of bronze letters. This is an extraordinary find for the quality of the architectural elements and for being one of the few inscriptions made in litterae aureae that have been preserved.

Key words: Necropolis; decumanus; mausoleum; Corinthian order; inscription; litterae aureae; earthquake. 


\section{Introducción: la necrópolis oriental y los mausoleos de la puerta sureste o 'Puerta de Carteia'}

La necrópolis oriental de Baelo Claudia (Tarifa, Cádiz) ocupa una superficie total de unas 4 ha y se extiende en ligera pendiente hacia el $\mathrm{s}$, desde la muralla de la ciudad. El proyecto Muerte y ritual funerario en Baelo Claudia está interviniendo en este sector desde 2012 conforme a un programa de investigación sistemático. Para delimitar los distintos trabajos arqueológicos que se han venido llevando a cabo, el espacio cementerial fue dividido en dos áreas, con una superficie de 1,5 ha cada una de ellas (Fig. 1). El Área 1 se corresponde con la zona más cercana a la playa, profusamente excavada a lo largo del s. xx, y de la que se han exhumado más de 1000 tumbas (Paris et al., 1926; Remesal, 1979). Limita al $\mathrm{N}$ con el antiguo camino de acceso al yacimiento, al E con algunas viviendas y restaurantes, al s con la playa y al o con el arroyo Churriana. El Área 2, cuya excavación se aborda en este artículo, engloba los sepulcros situados a unos $50 \mathrm{~m}$ de la puerta oriental de la ciudad, un sector aparentemente intacto que se ubica al $\mathrm{N}$ de la vía de acceso y al o del espacio vallado del aparcamiento. Bajo este último, la prospección con georradar acometida en 2013 documentó diversos mausoleos de entidad y la vía funeraria, posiblemente pavimentada, a menos de $2 \mathrm{~m}$ de profundidad de la superficie actual.
Las tareas iniciales se centraron en la reexcavación y estudio del Área 1, pues, al ser una necrópolis intervenida desde un siglo atrás, existía mucha documentación que había que revisar y ordenar (Prados et al., 2014). El principal resultado fue la recuperación del plano de la necrópolis incorporando

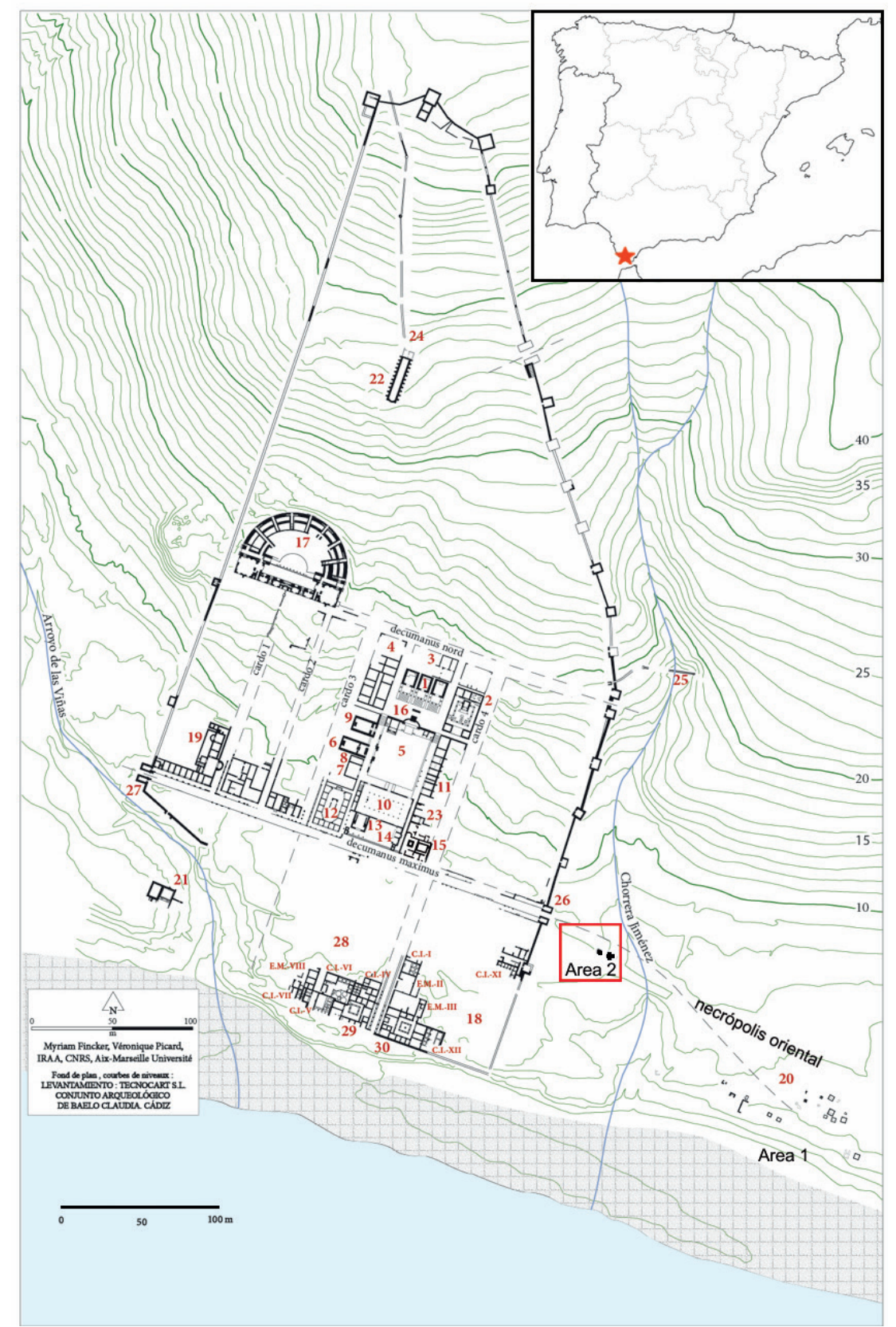

FIG. 1. Localización y planta de Baelo Claudia con indicación de las áreas de intervención de las necrópolis oriental. 


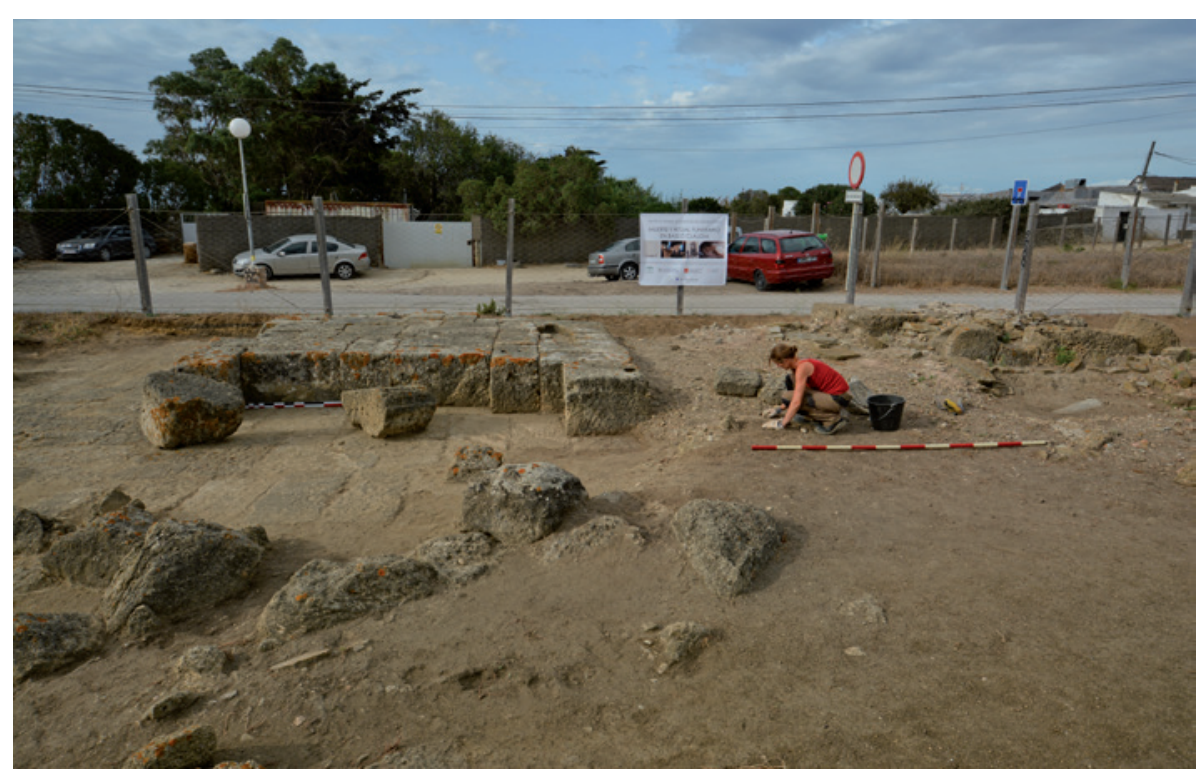

Fig. 2. Parte visible de los mausoleos al inicio de la intervención arqueológica.

en la zona de la puerta, lo que planteaba ciertos problemas topográficos (Fig. 2). A pesar de que uno de ellos -el T-31había sido dibujado por G. Bonsor entre 1917 y 1921 (Paris et al., 1926: fig. 62), no se sabía nada más, quedando pendiente tanto su adscripción cronológica como su posición respecto a la vía que en dirección este salía de la ciudad. Las recientes prospecciones geofísicas realizadas en el área del aparcamiento, contigua a esta zona de interven-

tumbas desaparecidas, excavadas o cubiertas por el paso del tiempo, así como las exhumadas en épocas recientes (Prados, 2015). En el último lustro, en cambio, se abrieron nuevas zonas, documentando sepulcros inéditos y una vía funeraria, cuyo registro ha sido fundamental para reconstruir el paisaje funerario y establecer la primera secuencia estratigráfica de la necrópolis (Prados y Jiménez, 2016).

La última campaña, desarrollada entre 2017 y 2018, se concentró pues en el Área 2, con la excavación de dos mausoleos ubicados cerca de la puerta oriental, llamada 'Puerta de Carteia' o 'Puerta de Mellaria' (Paris et al., 1926: 98), esto es, el acceso oriental a la ciudad. Se trataba, como se ha dicho, de una zona poco estudiada, a pesar de que junto a este sector se había excavado recientemente el decumanus, y, durante una intervención en la muralla, un conjunto de tumbas tardorromanas de tipo mensa, fechadas en los ss. v y vi (Arévalo et al., 2006; Bernal et al., 2015).

Los dos citados mausoleos -denominados T-31 y T-32- se encuentran dentro del actual espacio protegido y están integrados en el circuito de visitas al yacimiento. Ambos eran visibles en superficie antes de nuestra excavación y aparecían a una cota muy superior -más de $2 \mathrm{~m}$ - por encima del decumanus ción, habían documentado, como se ha adelantado, la continuidad del trazado de la vía sepulcral, que discurre justo por delante de los mausoleos. Estos dos monumentos, por tanto, se pueden relacionar con las élites locales y la fase más antigua de este sector cementerial, en función de su mayor tamaño y su posición preeminente junto a la puerta.

A pesar de los continuos expolios a que se habían visto sometidas, las dos estructuras, forradas de sillares, presentaban de inicio una enorme monumentalidad, quizás reflejo del periodo de esplendor que disfrutó esta ciudad durante los ss. I y II. Ya hemos aludido a la mayor altitud de estos monumentos respecto de las losas del decumanus maximus que socavaron el nivel tardorrepublicano en la zona de la puerta (Sillières, 2004), lo que parece reflejar una datación posterior a este acceso y a la propia muralla. Por esta razón, las primeras acciones se concentraron en solventar este problema topográfico, que fue resuelto de inmediato: ambos mausoleos hacen fachada con el decumanus, que asciende levemente según se aleja de la ciudad, lo que, sumado a un estado de conservación mejor del esperado, explica la diferencia de altitud y revela una cronología altoimperial similar a la del decumanus. 


\section{La excavación de los mausoleos: $\mathrm{T}-31$ y T-32}

La excavación en área ha pretendido ratificar esta propuesta de datación, al tiempo que ha permitido obtener información sobre las estructuras arquitectónicas en sí, e intervenir en los diversos sepulcros tardíos que las rodeaban. Al actuar de esta forma se ha podido conseguir una secuencia completa del abandono de la necrópolis y del proceso de colmatación de esta y de la vía sepulcral (Fig. 3). Al mismo tiempo, se han estudiado las fases tardorromanas de esta zona de la necrópolis. Se ha tratado, por todo ello, de una intervención que ha posibilitado fechar estos dos monumentos funerarios, observar la relación entre ellos y dar respuesta a algunas cuestiones topográficas y urbanas.

\subsection{El mausoleo T-31 y el diverticulum}

El mausoleo T-31 se intervino parcialmente. Antes de plantear la excavación se observaba un basamento de sillares de biocalcarenita muy expoliado, de más de $15 \times 15$ m de superficie, totalmente desprovisto de elementos decorativos, aunque arrumbados al pie se advertían algunos bloques de esquina con restos muy erosionados de pilastras. En la parte superior se había tallado un sepulcro antropomorfo que había sido dibujado por G. Bonsor (Paris et al., 1926: 99). Este hecho aportaba una información relevante: en época tardoantigua o medieval el mausoleo ya estaba en el mismo estado en que lo encontramos en la actualidad, luego su destrucción y expolio fue necesariamente anterior. En el

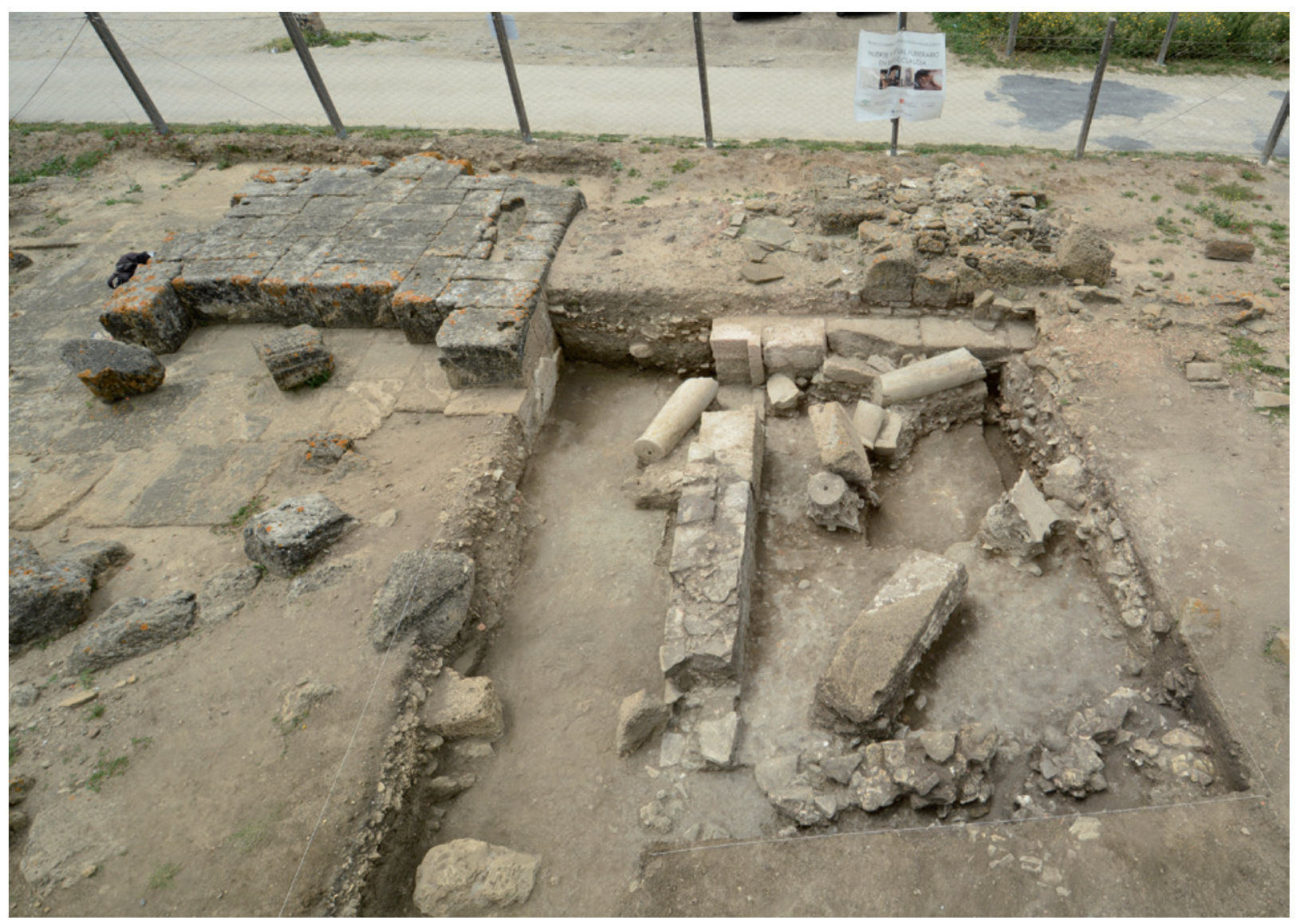

Fig. 3. Vista oblicua del área de intervención; en el centro, el diverticulum. 


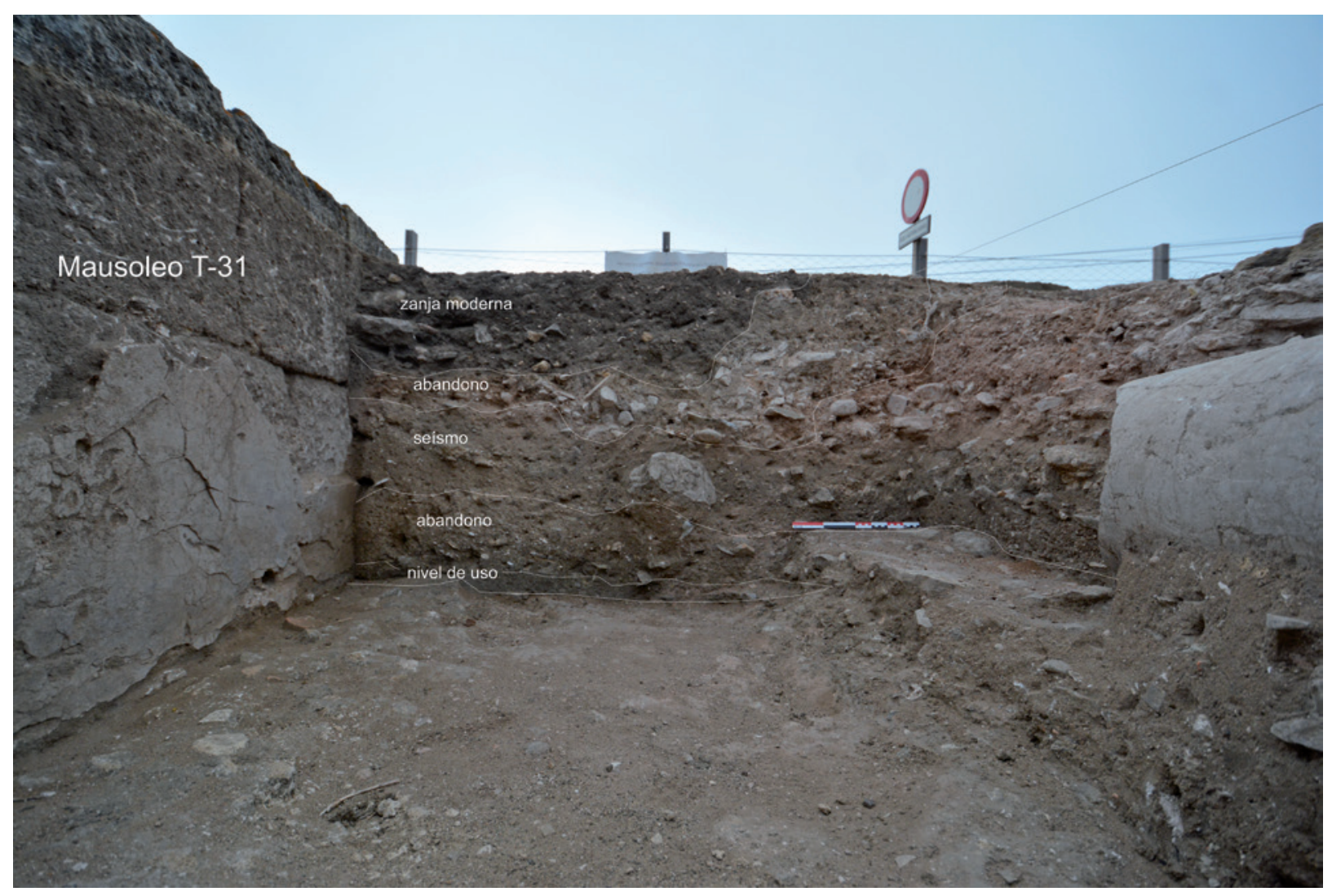

Fig. 4. Perfil estratigráfico sur del diverticulum, entre los dos mausoleos.

citado volumen los excavadores aluden a que este mausoleo “... qui remontait à une bonne époque, au temps de Claude ou Trajan, est rectangulaire, orné de pilastres cannelés et de chapiteaux corinthiens..." , lo que es muy interesante, aunque ya no queda rastro de los citados capiteles. La parte posterior del edificio no pudo ser excavada al quedar por debajo del recinto acotado del yacimiento y de la carretera actual que da servicio a los restaurantes. La intervención en su parte anterior permitió, en cambio, documentar numerosos elementos arquitectónicos, cornisas, pilastras y restos de su estucado. Pero esta zona delantera está muy alterada y erosionada, y no se ha documentado cultura material mueble asociada. Esta es la razón por la que decidimos concentramos en el espacio que separa ambos mausoleos.

Tratando de alcanzar su cimentación y los niveles constructivos, se excavó el espacio intermedio a fin de determinar el momento de construcción.
Esta intervención, además de alcanzar la cimentación de ambos edificios, como veremos, posibilitó realizar una correlación estratigráfica entre ellos, separados por un diverticulum de poco más de $2 \mathrm{~m}$ de anchura que discurrió en sentido norte-sur y unió el decumanus con la zona portuaria. Ya adelantamos que la estratigrafía ha corroborado que los dos mausoleos son prácticamente coetáneos y que forman parte del mismo proceso de urbanización de este espacio extramuros.

La excavación ha permitido documentar que el edificio se construye sobre el estrato geológico y a la par que el citado callejón o diverticulum. Sobre el nivel geológico, y anteriores a la construcción del edificio, se recogieron algunos materiales tardorrepublicanos, concretamente fragmentos de TSI. Por encima se han documentado materiales arqueológicos que se pueden fechar sin problema a lo largo de la primera mitad del s. I, y que están asociados al 
uso de esta calle. La intervención ha permitido confirmar también que los bloques de opus quadratum que conformaban el basamento de este mausoleo se encontraban estucados, conservándose in situ varias partes con restos de pintura (Fig. 4). Estos materiales posibilitan datar la construcción del monumento a mediados del s. I, es decir, en la primera fase de uso del espacio funerario oriental de la ciudad (Prados, 2017).

Del diverticulum se ha localizado su nivel de uso, compuesto por un estrato compacto de color amarillento que incorpora algunas lajas planas de piedra. En cota, este 'suelo' se encuentra $45 \mathrm{~cm}$ más alto que el nivel del decumanus en el umbral de la puerta de la ciudad. Esta es la ligera elevación que comentábamos al inicio, que representa la existencia de una suave pendiente que arranca desde la 'Puerta de Carteia' hasta esta zona de los mausoleos. Cabe referir que todos los materiales que apoyan sobre este paleosuelo, procedentes de su uso, se adscriben a cronología altoimperial. Formando parte del mismo nivel de circulación o uso se localizaron restos de fauna, concretamente espinas y vértebras de pescado.

Sobre los niveles de uso se constata un estrato de abandono general, sobre el que, como veremos, cayeron elementos arquitectónicos procedentes del derrumbe del mausoleo T-32 motivados por un seísmo, concretamente un fuste de columna y otros fragmentos de mármol. Este estrato presenta abundantes restos de materia orgánica y está muy poco compactado. El hallazgo de monedas acuñadas a mediados del s. IV entre este nivel y los elementos arquitectónicos será fundamental, como veremos más adelante, para tratar de fechar el seísmo que causó este derrumbe. Del mausoleo T-31 poco más se puede decir debido a su deficiente estado de conservación. En todo caso es importante indicar que el citado evento que supuso la destrucción de T-32 derribó también T-31.

La excavación de la superficie del callejón permitió localizar una tumba de cremación, muy sencilla, pero que estaba claramente asociada al mausoleo T-32, y sobre la que volveremos más adelante. Finalmente, sobre los restos del derrumbe de $\mathrm{T}-31$ se excavó un estrato arcilloso, muy plástico y de color negro que parece proceder de depósitos naturales del arroyo vecino, y que debió llegar por diversas crecidas. No presenta apenas material arqueológico y se pone en relación con el 'black level' que se documenta en otros puntos de la ciudad, sobre todo en el decumanus, atribuido a un evento marino de alta energía o tsunami (Röth et al., 2015; Silva et al., 2016). Aunque la presencia de bioclastos y otros elementos podrían identificarse con 'tsunamitas', no podemos afirmarlo con rotundidad, y nos inclinamos más a pensar en la citada crecida del arroyo. Este estrato cubre o apoya sobre todas las unidades descritas hasta ahora, por lo que es claramente posterior al abandono de este sector de la necrópolis hacia el s. vir. Además, durante la excavación de esta unidad estratigráfica, se localizaron dos monedas de la I República española (1873-1874) que sugerirían una formación bastante reciente.

\subsection{El Mausoleo T-32 o de Iunia Rufina}

Visible en planta al igual que su vecino, este edificio presentaba un peor estado de conservación, ya que el expolio le había desprovisto de muchos más bloques. Además, en torno a lo que quedaba en pie del mausoleo, se observaban distintos sepulcros tardíos, algunos rompiendo literalmente el basamento para ser encajados, y otros colocados justo al lado. Se trataba en todos los casos de tumbas de inhumación, algunas en sarcófago, que se habían ido asociando a la estructura previa que ya debía estar bastante arrasada en aquel momento. La enorme profusión de enterramientos llamaba la atención y, de algún modo, permitía vislumbrar que el edificio primigenio debió de tener cierta enjundia, dado el especial interés que se había tenido en conectar estos enterramientos con él.

Hemos de subrayar de inicio que no sabemos cómo era el coronamiento de la estructura, dado que estaba desmontado hasta el podio y de su núcleo solo se observan restos de opus caementicium. La excavación que vamos a describir a continuación es la que realizamos al pie del mausoleo, dentro de 
un acotado funerario que presentaba en la parte delantera, y que hacía fachada al norte con la vía sepulcral prolongación del decumanus, y al este con el diverticulum descrito en el apartado anterior.

Desde el inicio, la excavación del mausoleo T-32 permitió localizar algunos elementos de lo que debió de ser su alzado. Destacan dos columnas y capiteles corintios de gran calidad realizados en mármol, así como elementos decorativos esculpidos y pintados que formaron parte de la ornamentación. Estos hallazgos, perfectamente conservados, fueron apareciendo inmediatamente por debajo de los niveles de derrumbe. Sobre los escombros se pudo excavar una inhumación infantil que había sido depositada en un ánfora, sellando los niveles de destrucción. Tanto este enterramiento como los que hemos citado antes ponían de manifiesto que el valor funerario y simbólico de esta zona no se había perdido con el paso del tiempo.

La intervención conjunta de los dos mausoleos y del diverticulum que los separa permitió, como hemos adelantado, correlacionar estratigráficamente estas construcciones, al tiempo que se pudieron insertar dentro del complejo urbano extramuros (Fig. 5). La estructura localizada no solo se componía del mausoleo en sí, visible de inicio, como hemos dicho, sino de un muro que, partiendo desde el mismo monumento, dibujaba un acotado funerario de planta cuadrada. Sobre este muro, de $60 \mathrm{~cm}$ de anchura y $1 \mathrm{~m}$ de altura máxima conservada, se abría una puerta, bien delimitada por dos jambas y un umbral monolítico, que facilitaba su acceso desde el este, es decir, desde el diverticulum.

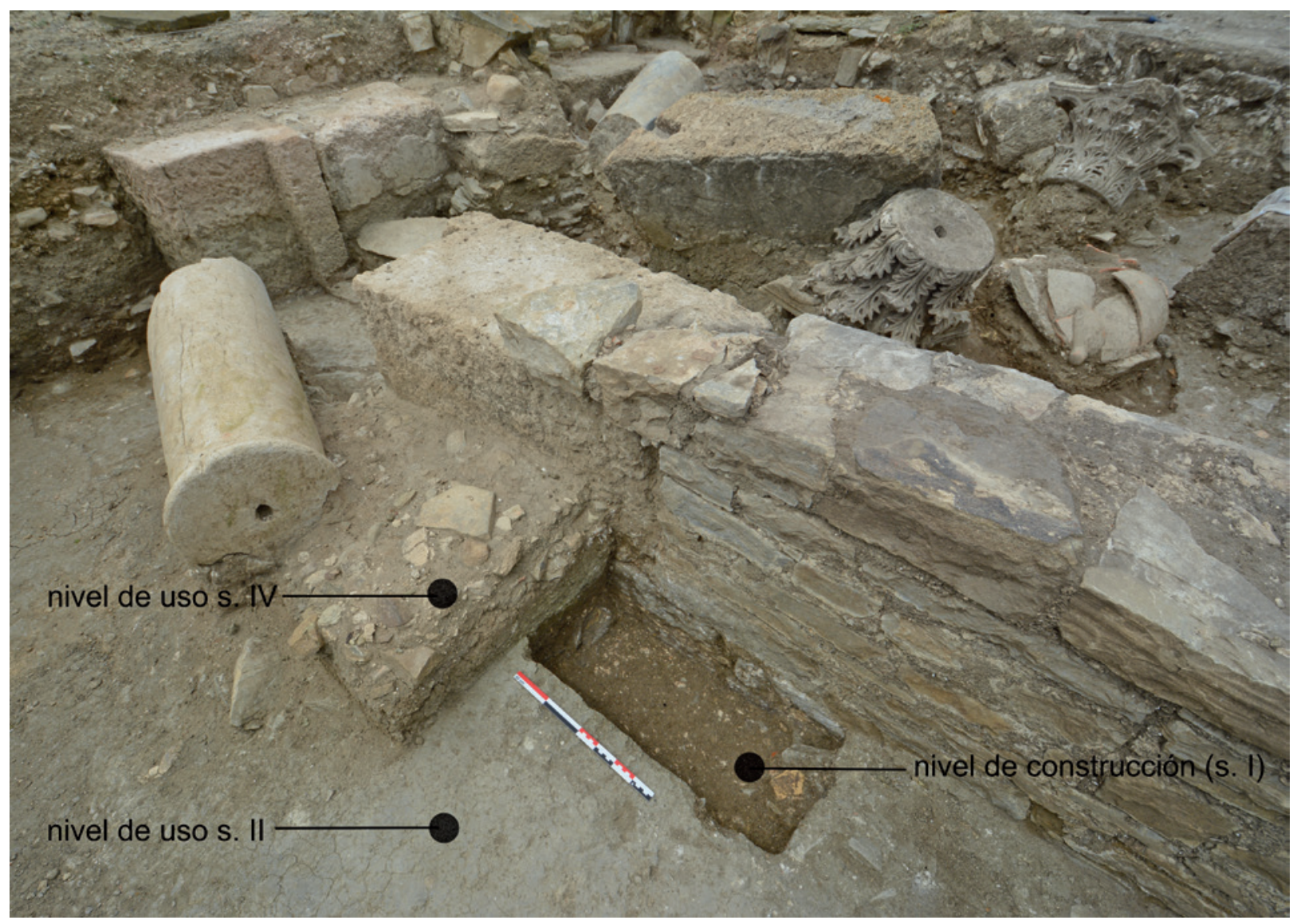

FIG. 5. Excavación del exterior del acotado funerario de la T-32 y fases. 


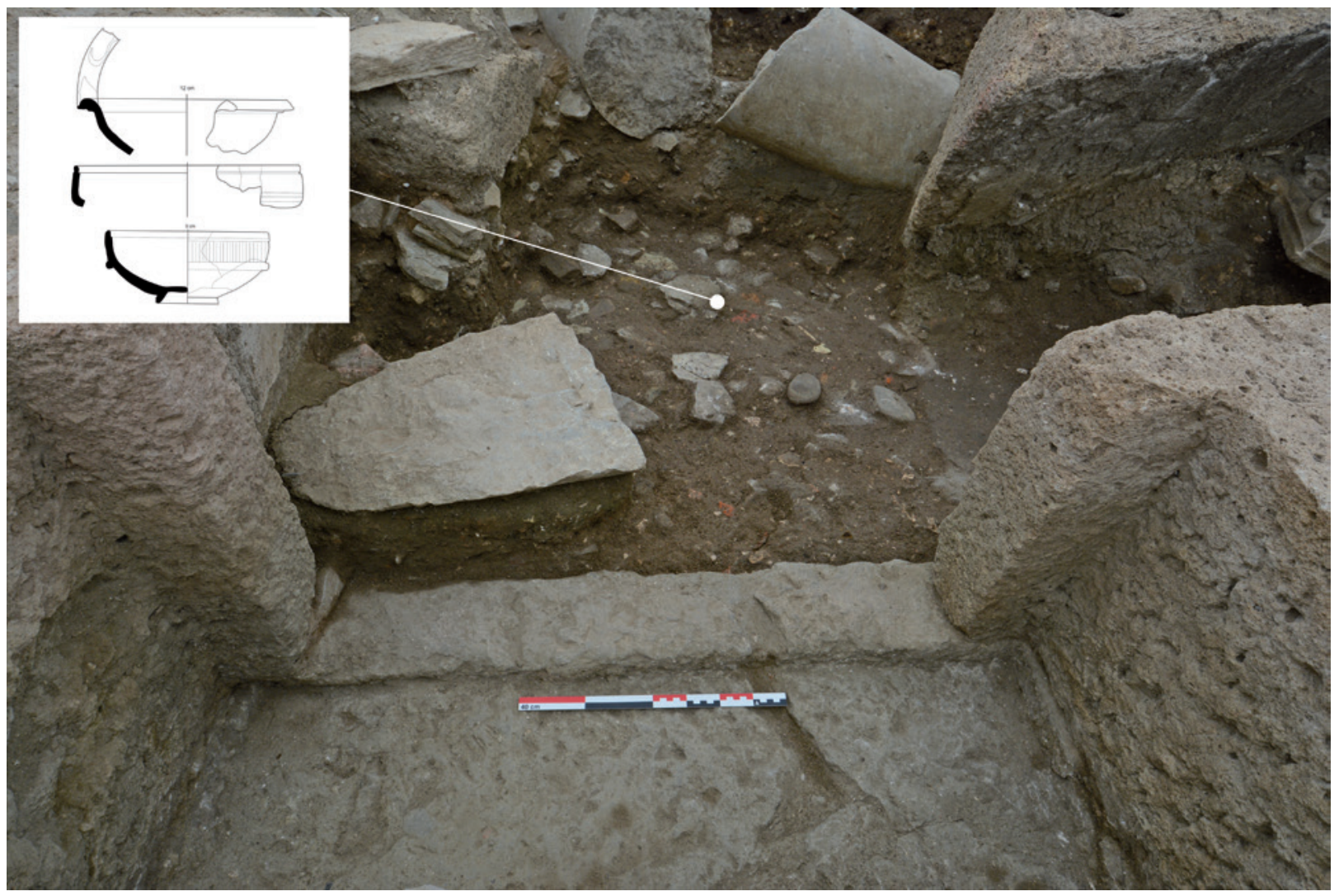

Fig. 6. Umbral de acceso al acotado funerario; bajo el derrumbe se observan los niveles de uso y de abandono.

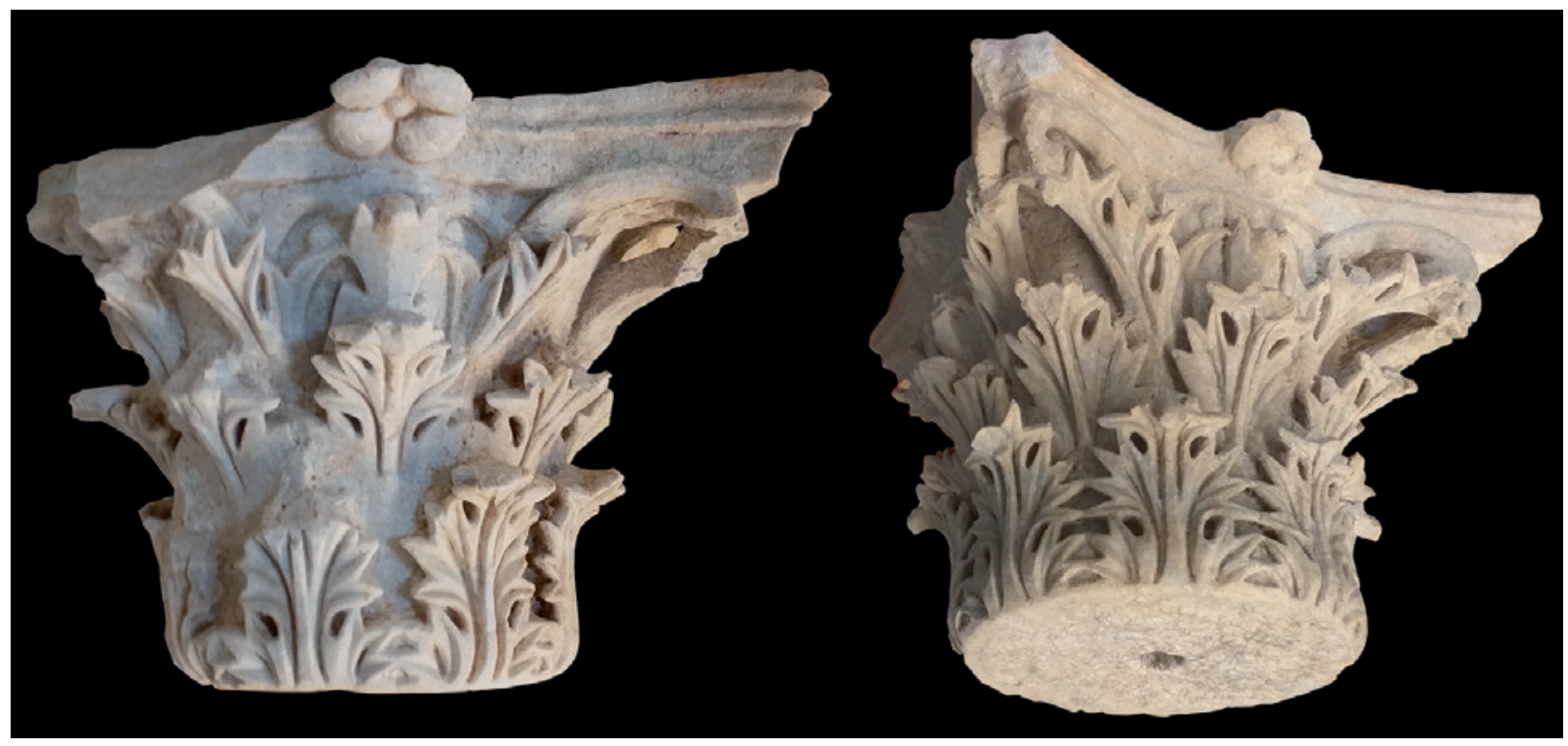

FIG. 7. Capiteles corintios del mausoleo T-32. 
La excavación del interior de este acotado ofreció una información muy completa de toda la secuencia, ya que se agotaron los estratos hasta alcanzar el geológico. En sentido inverso a la excavación, y en orden cronológico, se documentó un estrato asociado a la construcción de los mausoleos. En él se recogieron materiales -fragmentos de TSI, TSG y una base de paredes finas- que pueden datarse en época de Tiberio/Claudio y, con ello, una fecha post quem para la construcción del mausoleo. El suelo de uso del acotado fue realizado mediante tierra amarillenta muy compactada, de unos $10 \mathrm{~cm}$ de espesor. Por encima de esta tierra la excavación permitió localizar materiales relacionados con sus últimos usos, sin constatar ninguna deposición funeraria. La abundancia de materia orgánica, como carbones, huesos de suidos, bóvidos y espinas de pescado, parece reflejar los rituales que se debieron desarrollar dentro de este espacio. Junto a la fauna, se recogieron varios remaches metálicos, una moneda en bronce de Trajano y alguna otra del todo ilegible. Los fragmentos cerámicos recuperados correspondían a formas abiertas, casi completas, de TSG y de Ts marmorata, que vinculamos lógicamente con la celebración de ritos de comensalidad. También se exhumó el tercio inferior de un ánfora altoimperial, recortada ex profeso para contener una ofrenda, que presentaba restos de un ave en su interior. Los materiales aludidos se pueden datar sin problema a lo largo de los ss. I y II ofreciendo, por tanto, una cronología clara para la vida del monumento. La cuestión es que por encima de estos estratos se localizó uno de abandono, con un importante aporte sedimentario, que señalaba el momento en que este espacio, y seguramente todo el mausoleo, entró en desuso.

Sobre este nivel de abandono, de una potencia nada desdeñable de entre 20 y $40 \mathrm{~cm}$, y que puede fecharse durante el s. III como veremos después, es donde se depositaron todos los elementos arquitectónicos del monumento una vez que aconteció el evento sísmico que lo derrumbó violentamente (Fig. 6). De los materiales que ayudan a fechar este abandono destacan varias monedas, dos de ellas ubicadas además bajo los elementos marmóreos derribados por el seísmo. Se trata de un hallazgo muy relevante que ayuda a establecer una datación precisa, post quem, para el evento y sobre el que trataremos con más detalle en el apartado siguiente.

Los elementos arquitectónicos que formaban parte del alzado del mausoleo aparecieron completos, aunque fragmentados por el fuerte impacto. Destacan los dos capiteles monolíticos, en buen estado de conservación (Fig. 7). Uno de ellos se localizó -casi en posición primaria si se nos permite la expresión- bajo un fragmento de dintel estucado que presentaba unas medidas de $116 \times 34 \times 48 \mathrm{~cm}$. Junto al capitel, de estilo corintio asiático con hojas de acanto espinoso, se recogieron otros fragmentos de elementos decorativos en mármol y algunos fragmentos de las volutas. El otro capitel apareció a más de $2 \mathrm{~m}$ de distancia desde la vertical del mausoleo. Muy similar al anterior, aunque no idéntico, presentaba el mismo estilo y las mismas dimensiones, ambos con un kalathos de 78 x 40 x $34 \mathrm{~cm}$. Los dos capiteles, y las columnas que los acompañaban y que cayeron junto a ellos, formaban parte del mismo conjunto decorativo.

El orden corintio asiático con acanto espinoso se conoce desde el s. I (Rohmann, 1998), con algunos ejemplos significativos en Iliria ya a principios del II, como es el caso del monumento de Agonothetes en la ciudad de Apollonia (Von Hesberg y Eck, 2010). Para los ejemplos hispanos ha sido datado un siglo después, en época severiana (Ramallo, 2004; Rodríguez, 2004), si bien nuestros ejemplares se asemejan a algunos descritos por P. Pensabene procedentes de las termas del foro de Ostia, fechados en el s. II (Pensabene, 1973: 94). Retrasar estos capiteles al s. III supondría que el mausoleo tuvo una decoración distinta al inicio y que habría sido sustituida posteriormente por esta que se describe. Ello no encaja con lo que dicta la estratigrafía en nuestra excavación, que muestra un nivel de abandono durante el s. III acorde con el momento de retroceso que vive la ciudad. Así, tomando en consideración los contextos estratigráficos que presentamos, junto al paralelo ostiense, proponemos adelantar la introducción de estos órdenes al s. II. La cuestión es que en estos capiteles el uso del trépano y lo arriesgado en la manera de ejecutar los elementos aéreos no tiene nada que 
ver con los ejemplos del s. III, y quizás podría ser un rasgo de antigüedad con respecto a capiteles más macizos, con pencas de acanto y volutas mucho menos estilizadas y aéreas ${ }^{1}$.

El elemento más destacado de entre los que cayeron en el interior del acotado funerario es el otro fragmento mayor de arquitrabe o dintel con dos caras estucadas (la anterior y la inferior). Estaba unido al que hemos citado anteriormente mediante una mortaja cubierta con una grapa de plomo, que localizamos al pie, en uno de sus lados menores. El bloque paralelepipédico, de unas medidas de $175 \times 34$ x $49 \mathrm{~cm}$, fue arrojado a más de $2,5 \mathrm{~m}$ de distancia desde la vertical del mausoleo, cayendo su cara vista boca abajo (Fig. 8). Más adelante trataremos sobre esta pieza y su magnífica inscripción funeraria, con letras de bronce. La forma en la que cayó, con la inscripción hacia abajo, es la causa de que se haya preservado intacta hasta ahora.

De lo que quedara en pie sabemos poco; fue sistemáticamente expoliado una vez derrumbado. Hay algunos bloques en el entorno reutilizados como parte de sarcófagos y otros formando parte de estructuras funerarias tardías. No hay rastro de tegulae y tan solo podemos inferir, gracias a la excavación del acotado funerario, que las deposiciones sepulcrales debieron situarse en el interior del mausoleo, seguramente en loculi creados a tal efecto. La razón es que en el espacio acotado no se ha detectado ninguna tumba y sí en cambio, como se ha visto, abundantes restos de las celebraciones de rituales, especialmente los relacionados con los banquetes funerarios (Fig. 6).

Una vez derrumbado el edificio y habiéndose generado un tell artificial, tenemos constancia de que el uso funerario se mantuvo, aunque con unas estructuras mucho más modestas. Ya hemos mencionado la deposición funeraria de un individuo infantil en ánfora (Fig. 9). Se trata de la inhumación de un perinatal, con la cabeza al oeste y sin ajuar, a excepción de unos pocos restos de ictiofauna que le acompañaban dentro del ánfora. El contenedor

1 Agradecemos los comentarios sobre los capiteles de los profesores H. von Hesberg, de la Univ. zu Köln, y O. Rodríguez Gutiérrez, de la Univ. de Sevilla. es un ánfora olearia Dressel 23/Keay XıIIa, un tipo fabricado durante el s. IV y que durante la primera mitad del s. v sirvió para exportar el aceite del valle del Guadalquivir (Keay, 1984; Remolà, 2000; Berni y Moros, 2012).

Sobre el podio del mausoleo, y adaptada a los restos arquitectónicos caídos, se excavó una sepultura que presentaba un enterramiento múltiple en su interior -dos individuos adultos y tres infantiles- ${ }^{2}$. Realizada con algunos bloques de piedra, fragmentos de mármol procedentes del mausoleo y ladrillos (Fig. 9), presentaba en uno de sus lados mayores, concretamente el norte, la estatua femenina que se conserva en el museo del yacimiento, formando parte de la cista. Esta escultura había sido localizada durante unos trabajos de limpieza y acondicionamiento acaecidos en 2001. Se trata de un tipo bien conocido y relativamente abundante en la Bética, que fue empleado como soporte en serie para los retratos de las élites provinciales (Baena, 2000, 2009). Aunque inicialmente fue publicada como proveniente del foro (Loza, 2005; Gómez, 2014: 16), su emplazamiento, sumado a la estructura del mausoleo y a la inscripción, nos lleva a proponer que se pudo tratar del retrato funerario de la propietaria. La escultura, realizada en mármol de Mijas por un taller provincial, representa el tipo Ceres-Poggio Imperiale y ha sido datada en la primera mitad del s. II (Loza, 2010; Beltrán y Loza, 2012: 49).

Saliendo del acotado, pero ubicado en contacto con el muro perimetral, se localizó un enterramiento de cremación, como se ha comentado anteriormente. Es importante referirlo porque estaba claramente asociado al mausoleo, como si se tratase de alguien próximo a la familia, pero no de pleno derecho, quizás un cliente, un liberto o un esclavo, ya que no ocupaba el espacio principal (Fig. 9). La tumba estaba excavada en el diverticulum y presentaba un canto rodado colocado a modo de estela funeraria junto a diversos elementos rituales claramente postdeposicionales: un clavo de hierro, hincado junto a la estela, y una de esas extrañas piezas amarillas de cerámica, localizadas tanto en

2 El estudio antropológico ha sido realizado por C. M. Román, de la Univ. de Granada. 


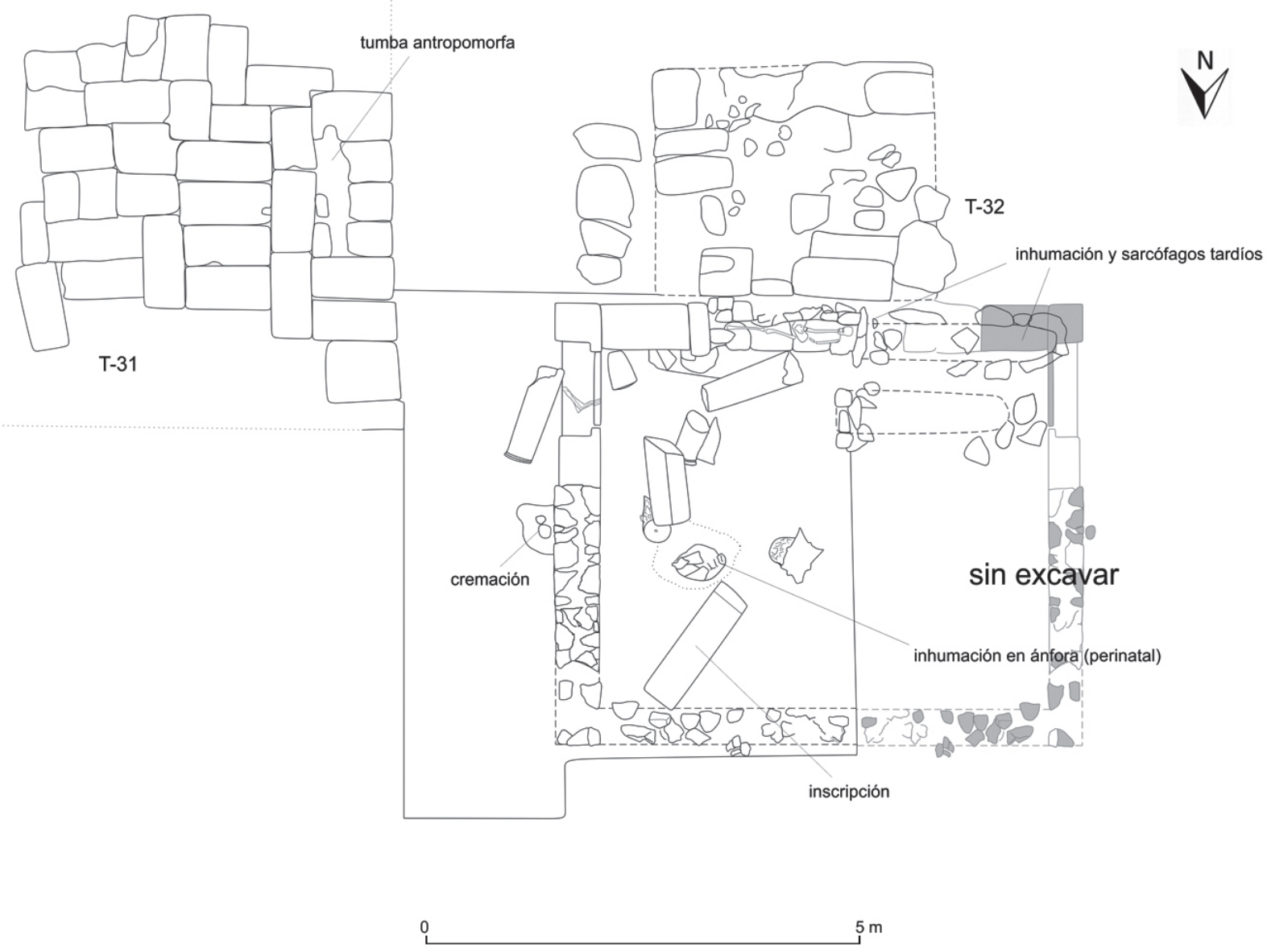

Fig. 8. Planta de la intervención arqueológica.

la necrópolis de Baelo como en la de la Silla del Papa, de tan difícil interpretación (Prados, 2017: 76 y fig. 2). Se trata de un sepulcro muy similar a los que se conocen por toda la fase altoimperial de la necrópolis oriental fechados a lo largo del s. I, mayoritariamente en época claudioneroniana (Prados y Jiménez, 2015; Prados, 2017). De hecho, entre los materiales asociados a esta deposición, como algunos de los que rellenaron su fosa, se localizaron fragmentos de TSI, TSG y un asa de lucerna del tipo Dressel 14, 15 o 17 que podría datarse en la segunda mitad del s. I. Cabe subrayar que este enterramiento es posterior al acotado, pues fue excavado sobre niveles de la calle que apoyan sobre el muro perimetral.

\section{El colapso de los mausoleos. A vueltas con el terremoto del s. IV}

Ya hemos aludido a que los dos mausoleos habían sido expoliados, si bien la excavación arqueológica permitió documentar otros elementos arquitectónicos caídos al pie. La naturaleza del desplome de todos estos elementos, sin presentar sedimentación interfásica entre ellos, sumado a que se depositaron sobre un mismo estrato y a la misma cota, indica con total claridad que se desplomaron en un mismo momento. A esta cuestión hemos de sumar que la base, que no sufrió un gran desplazamiento, presenta diversas grietas, siempre en sentido SO-NE, que es el mismo que siguieron todos y cada uno de 
los elementos constructivos y decorativos derrumbados (Fig. 10).

El muro oriental del acotado funerario presenta de igual manera grietas y un desplazamiento lateral de alguna hilada por esta misma acción. Todo ello, sumado a la distancia a la que aparecen las columnas, los capiteles y el arquitrabe del monumento, superior a los $2 \mathrm{~m}$ desde el basamento, refleja que se trató de una sacudida muy violenta (cf. Figs. 5 y 9). La suma de estos factores y las citadas grietas son motivo más que suficiente para buscar la explicación del derrumbe en un terremoto. Además, la excavación arqueológica de la unidad estratigráfica sobre la que cayeron los elementos arquitectónicos propició el hallazgo de abundantes materiales arqueológicos, algunos especialmente interesantes porque ofrecían una datación post quem para este seísmo. De entre estos materiales destacan dos monedas de Constancio II. Una de ellas, en magnífico estado de conservación, es un $A E 2$ con reverso tipo FEL TEMP RE - PARATIO (RIC viII, 135) acuñado c. 350 d. C. en Antioquía. La otra es un $A E 4$ con reverso tipo GLO - RIA EXERC - ITVS también de ceca oriental y acuñado en las décadas centrales del s. IV d. C. (RIC VIII, 54?) $)^{3}$.

Ambas presentan en el anverso el retrato del emperador y la leyenda DN CONSTAN.TIVS.PF.A$V G$, desarrollada $D$ (ominus) $N$ (oster) Constantius P(ius) F(elix) Aug(ustus).

Como hemos dicho, la fecha de acuñación de estas monedas va a ser fundamental para ubicar cronológicamente el evento sísmico. Además, ya habíamos comentado que, sobre los escombros del derrumbe, y excavada en un nivel que apoyaba sobre uno de los dos capiteles, pudimos excavar una inhumación infantil en un ánfora Dressel 23/Keay xirra. Este eventual contenedor funerario ofrecía una fecha muy interesante, pues parece que fue empleado hasta mediados del s. v. Una y otra datación, post quem y ante quem, situaban el terremoto en la segunda mitad del s. Iv o en las primeras décadas del v.

3 Estas piezas han permitido una catalogación preliminar que solo ofrece alguna pequeña duda respecto al taller de origen, por lo que se proporcionan las correspondientes referencias al RIC. Agradecemos a la Dra. C. Blázquez (Univ. de Salamanca) la clasificación de este material.
La cuestión es que este célebre terremoto, que parece que afectó a puntos de la costa malagueña (Silva et al., 2005), había sido detectado por los arqueosismólogos que trabajan en Baelo (Menanteau et al., 1983; Silva et al., 2005: apart. 8.1) y datado entre el 365-395, en una fecha acorde con nuestro registro. Del estudio arqueosísmico se desprende que toda la ciudad padeció un desplazamiento anómalo del suelo hacia el oeste, oblicuo a la pendiente principal en sentido sur, con colapsos y derrumbes de paredes y columnas que, como en el caso del mausoleo T-32, reflejó un estrés que actuó siguiendo la orientación SO-NE.

Aunque en trabajos recientes la fecha de este terremoto ha sido adelantada al s. III por miembros del mismo equipo de investigadores (Silva et al., 2009; Silva et al., 2016: 5), nuestra excavación retoma el debate y hace necesario volver a contemplar la fecha de la segunda mitad del s. IV por motivos obvios. Creemos que los hallazgos de materiales datantes $\mathrm{y}$, sobre todo, del numerario son evidencias irrefutables en este sentido.

Hemos de recordar que en julio del año 365 tuvo lugar un importante terremoto en Creta que desencadenó un potente tsunami con gran impacto en Tripolitania y en Alejandría (Stiros, 2001). Resulta reveladora la coincidencia en las fechas, aunque seguramente se trate en nuestro caso de un evento de ámbito regional, como los que se documentan a lo largo del s. Iv (Silva y Rodríguez, 2014; Silva et al., 2016: 5), sugeridos también para Carteia (Jiménez, 2017: 109-110), y cuyo epicentro pudo estar en algún punto del golfo de Cádiz.

De lo que no cabe duda es de que el movimiento brusco a que se vio sometido el mausoleo supuso el derrumbe de su fachada, junto a todos los elementos decorativos que conformaban un templete o edículo. El arquitrabe, que estaba dividido en tres piezas, fue proyectado junto a las columnas. La porción mayor, que presenta el epígrafe funerario con letras de bronce, cayó boca abajo y por ello el metal, al no estar visible, no fue expoliado. Uno de los fustes rodó hasta el callejón y fue fracturándose en varias partes; el otro se desplazó con su capitel, cayendo en su posición original. Los 
capiteles monolíticos de mármol, aunque golpeados, pudieron ser recuperados completos como ya se ha dicho.
La ausencia de molduras, tegulae o material latericio, nos indica que no existió una cubierta sobre el arquitrabe ni un frontón, y por ello proponemos

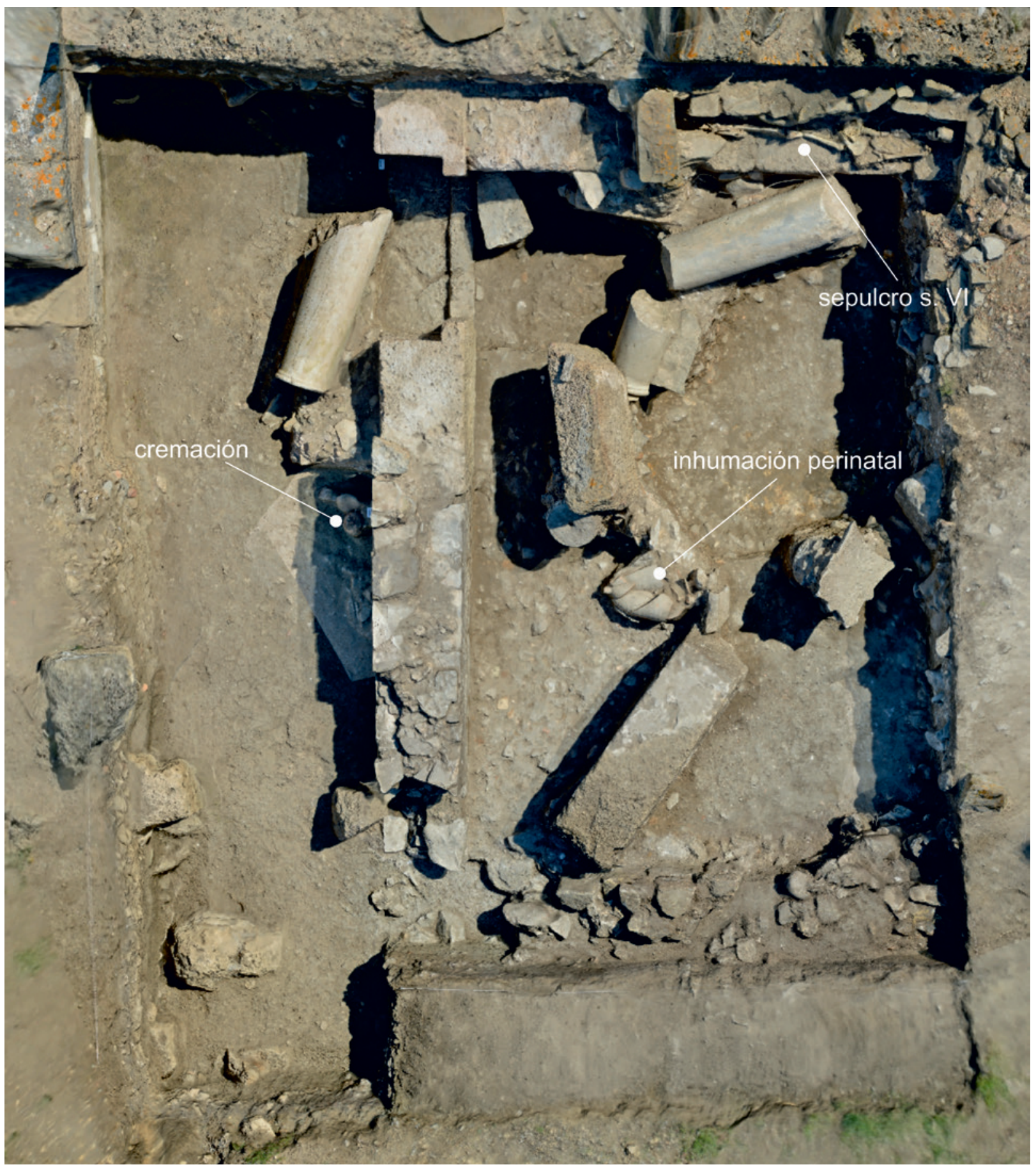

FIG. 9. Ortofoto del área excavada de la T-32. 


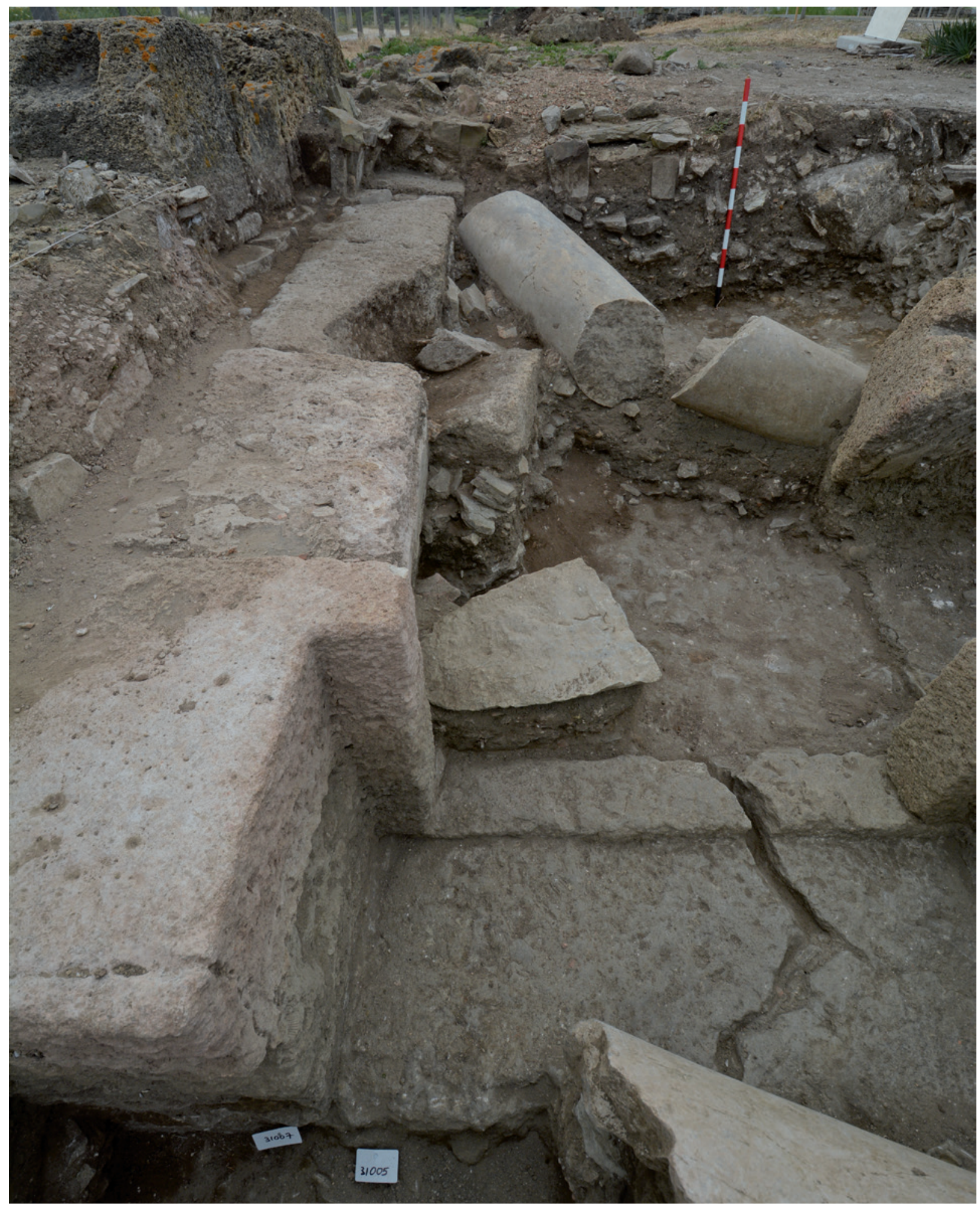

FIG. 10. Evidencias del seísmo en el acotado funerario de la T-32. 
que se trataba de un edículo o templete con fachada adintelada. Del resto del edificio, o de lo que quedó en pie, poco o nada sabemos, porque fue expoliado después del seísmo. La suerte es que el derrumbe generó una escombrera que protegió las piezas marmóreas y solo al azar debemos la conservación de la inscripción. Según lo que conocemos de la ciudad, este terremoto condujo a un fuerte cambio en la estructura urbana, arrancando un periodo de clara decadencia, que vino a sumarse a la que ya había iniciado décadas antes, durante el s. III (Sillières, 1997). Cabe recordar que en otros edificios de Baelo Claudia, como la basílica, se constatan caídas de columnas, deformaciones de muros y pavimentos en este mismo momento (Silva et al., 2005; Silva y Zazo, 2016).

\section{La inscripción funeraria}

Una de las piezas más interesantes encontradas es el citado bloque de piedra arenisca de 175 x 34 x $49 \mathrm{~cm}$, que estaba unido por una grapa de plomo a otro como parte del arquitrabe de la entrada del mausoleo (Fig. 11). Sus caras visibles, exterior e inferior, están revestidas por una capa gruesa de estuco de $1,5 \mathrm{~cm}$ y otra más fina de enlucido de unos $5 \mathrm{~mm}$. En la cara frontal encontramos un conjunto de diecisiete letras y cinco puntos de forma triangular.
Todos están fundidos en bronce, las letras son de sección triangular, con una arista central que constituye la parte más saliente y tienen una altura que varía entre 12 y $14 \mathrm{~cm}$.

El buen estado de conservación de la pieza no permite observar el reverso de las letras, cuántas espigas tiene cada una y cómo traban con el sillar. Las $D$ y $N$ de la primera línea, las más próximas al borde, dejan ver parte de una espiga superior, de sección curva. Estas espigas traspasan la capa de revestimiento y se anclan en la propia piedra, aunque no podamos conocer los detalles. El agarre debió de ser efectivo, puesto que el sillar fue despedido violentamente a varios metros de su emplazamiento original, como consecuencia del movimiento sísmico, sin que se desprendieran ni el revestimiento ni las letras, que actuarían como tirantes de refuerzo en este momento.

Por lo demás, en el momento del descubrimiento las letras mostraban aún vestigios del color dorado que las haría resaltar sobre el enlucido $-c f$. la letra A en la Fig. 11-. Este es hoy de color blanco, sin que se hayan podido detectar vestigios de otro color ni aun con el empleo de fotografía infrarroja.

Las letras son de buena calidad y dispuestas con orden, aunque su ordinatio deje traslucir irregularidades. Unas están ligeramente fuera de sitio -caso de las dos M, de la A de $M A N$ y de la F de $R V F$, siendo este último el más destacado); otras están

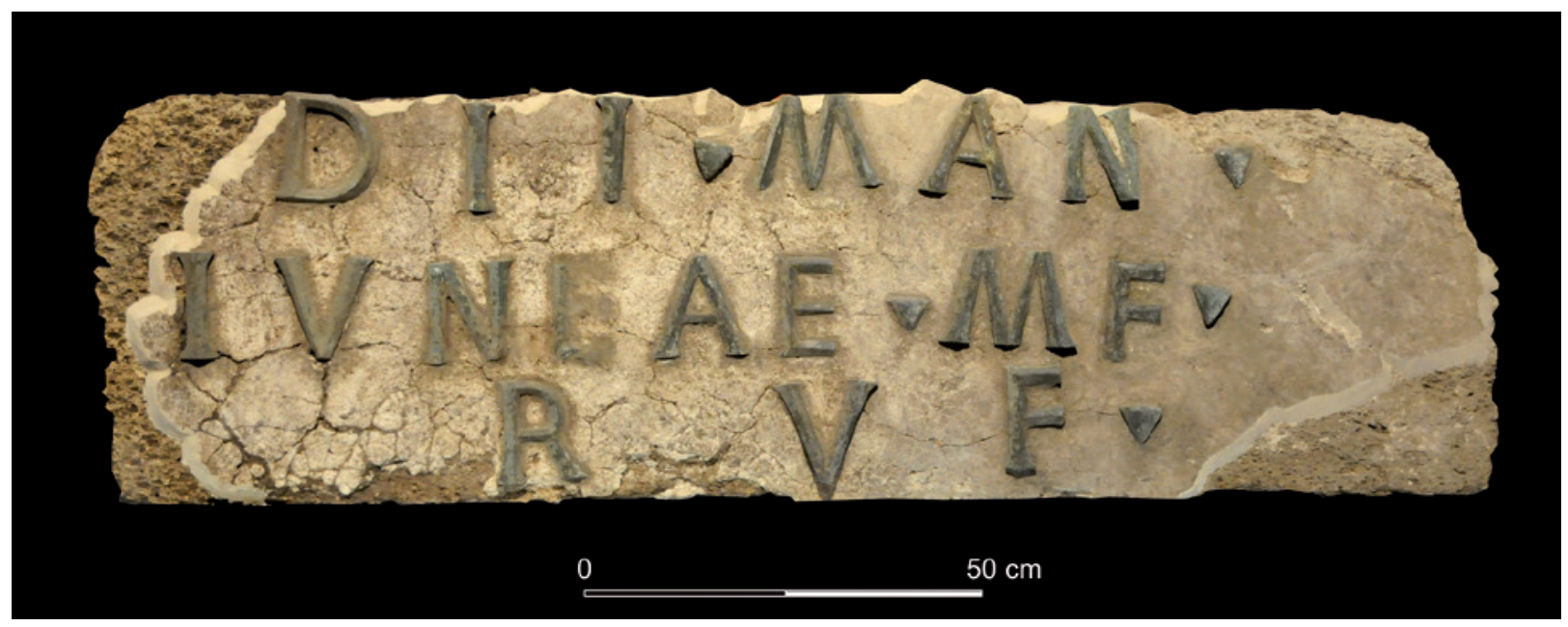

FIg. 11. Epigrafe de Iunia Rufina. 
inclinadas, hacia la derecha, como la A de $M A N$ y la F de $M F$ y ligeramente hacia la izquierda la $\mathrm{R}$ de $R V F$. La separación entre letras varía. En la primera y tercera líneas hay más espacio entre ellas que en la segunda, sobre todo en $D I I$ y $R V F$. En esta última palabra, la separación entre $\mathrm{R}$ y $\mathrm{F}$ es mucho mayor que entre v y F. En la segunda línea, la separación anómala entre la $\mathrm{N}$ y la i de IVNIAE es un caso particular que más abajo comentaremos. Los signos de interpunción triangulares tienen el eje

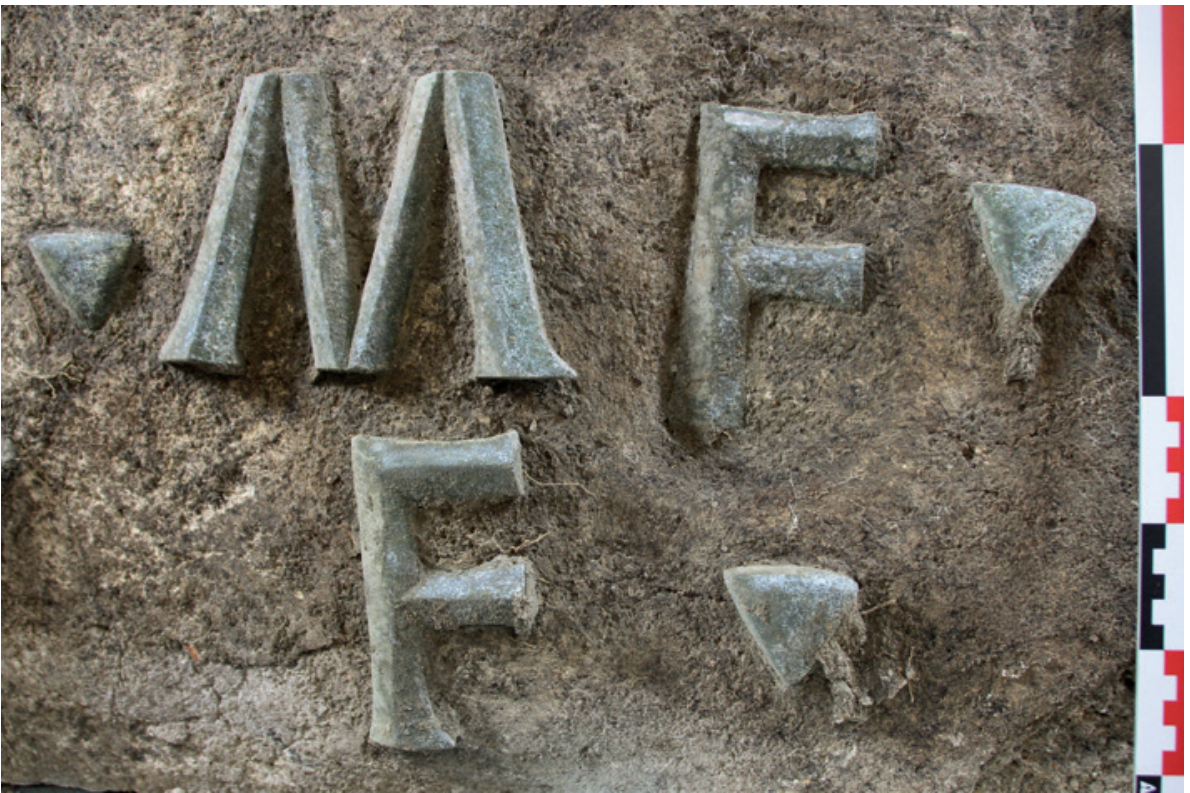

Fig. 12. Detalle de la reutilización de letras: abajo se observa una letra F original y arriba otra realizada a partir del estucado parcial de una letra $E$. más largo de arriba abajo,

aunque en el primero la inclinación es de izquierda a derecha ${ }^{4}$. Falta un punto entre la $\mathrm{m}$ y la $\mathrm{F}$ y en cambio se incluyen interpunciones al final de cada línea (Fig. 12). Es de destacar que la $\mathrm{N}$ final de $M A N$ tiene el trazo vertical derecho doblado hacia el interior. Las letras v, tanto en IVNIAE como en RVF, parecen ligeramente diferentes. Más corta y de trazo más grueso la primera, más alta, de trazo más fino y ligeramente curvo la segunda. Aunque el que las letras estén parcialmente embutidas en el enlucido que recubre el sillar dificulta su visión completa.

Lo más curioso e interesante es el hecho de que dos de estas letras, la segunda I de IVNIAE y la $\mathrm{F}$ de $M F$, no son en realidad ni una I ni una $\mathrm{F}$ sino dos E, algunos de cuyos trazos horizontales han sido tapados, de manera deliberada, con la capa de enlucido; mediante la ocultación de los tres trazos horizontales en el primer caso ${ }^{5}$, y del trazo inferior en el

4 Según Stylow (1995: 222), el uso sistemático de interpunciones triangulares con un pico hacia arriba es indicio de fecha preflavia, lo que no sería nuestro caso, puesto que ninguno de los puntos está en esta disposición.

5 En las fotografías tomadas en el momento del descubrimiento se observa con claridad la existencia de estos segundo (Fig. 12). De esta manera se explica el gran espacio que queda entre la i y la a de IVNIAE y la diferencia en el remate inferior entre la f de $M F$ y la de $R V F$.

Es un epígrafe de calidad, con letras también de calidad, pero que presenta varios defectos. En primer lugar, la disposición de las letras con diferencias de orientación y de ubicación, que seguramente serían menos visibles en su emplazamiento original que hoy, observada la pieza desde muy corta distancia. En segundo lugar, el empleo de letras que no se corresponden con las que debían ser y que han sido enmascaradas con el propio revestimiento.

Este hecho plantea diversas interpretaciones. La primera, que se trate de un error de quien hizo la inscripción, colocando una $\mathrm{E}$ donde debía ir una I. La forma Iulia es bastante más frecuente que Iunia y el espacio entre la $\mathrm{E}$ y la A que le sigue es el que corresponde, sin que se haya intentado hacer más pequeño aproximando las dos letras. Pero no es la única letra equivocada. La F de $M F$ es también una E enmascarada, lo que invalida la hipótesis del error.

trazos en la I, debido a la humedad de la piedra, mientras que es mucho menos perceptible en el caso de la F. 
La inclusión de ambas letras y su posterior enmascaramiento debió ser un hecho consciente, al menos en la segunda. La explicación más lógica junto al error sería que se tratase de letras recicladas, no hechas exprofeso para este monumento; el que la $\mathrm{N}$ de $M A N$ esté dañada apunta en esta dirección. Sin embargo, la pieza es de una gran solidez y calidad y la fecha aportada por el contexto estratigráfico indica que la inscripción debió colocarse en su lugar a lo largo del s. II d.C., momento en que el fenómeno del reciclaje todavía no era habitual.

La dedicatoria sería la siguiente:

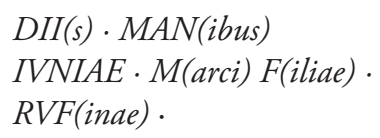

$\mathrm{O}$, lo que es lo mismo, "Para los dioses Manes de Junia Rufina, hija de Marco".

La lectura, muy clara, presenta un par de problemas. El primero es la interpretación de la primera línea: $D I I \cdot M A N$., que podría desarrollarse en nominativo como dii man(es) o en dativo plural como dii(s) man(ibus). Aunque ambas fórmulas son posibles, nos decantamos por la segunda, bastante más extendida en el ámbito epigráfico en general y en la Bética en particular, si bien en su versión abreviada $D M$ o $D M S^{6}$.

La fórmula total o parcialmente desarrollada es mucho menos frecuente que la abreviada y se ha venido considerando que también es anterior, aunque en los últimos tiempos se tiende a poner en duda esta aseveración (Tantimoniaco, 2014: 330). Casi todos los autores coinciden en que estas invocaciones a los dioses manes se datan a lo largo de los ss. II y III d. C., aunque las hay en el I d. C. e incluso a

6 En el catálogo Epigraphic Database de Heidelberg (abreviado EDH) encontramos una referencia en la forma Dii Manes y dos en la versión Dei Manes; solo la primera de ellas es una fórmula de consagración (Dii Manes/sacrum / [-?] Iulio/Celer[i]) (AE 1998, $0088=\mathrm{EDH}, \mathrm{HD} 03410$. Siglo I d. C.), mientras que en las otras $(\mathrm{AE} 1939,0047=\mathrm{EDH}$, HD022452; CIL 02, 02255 = EDH, HD028466, año 19 a. C.) la expresión es claramente sujeto de una acción verbal. De la forma Deis Manibus encontramos tres, mientras que de Diis Manibus, que correspondería a la nuestra, aparecen 105 ejemplos. mediados del I a. C., como un ejemplo de Córdoba del 19 a. C., bajo la forma Dei Manes receperunt (EDH, HD028486; Stylow, 1995: 223).

Sobre los epígrafes de Baelo (Bonneville et al., 1988; Le Roux, 2009: 163-174), E. Gozálbez Cravioto (2002: 4-8) llama la atención acerca de que, de 33 epígrafes funerarios documentados hasta esa fecha en la ciudad, al menos 22 lo hacen bajo la invocación a los dioses manes, por regla general en la forma abreviada $D M$, al contrario de lo que ocurre en la Bética y la Lusitania, donde predomina la fórmula $D M S$, que es la preferida también en la vecina Cádiz. La fórmula $D M$ es, por el contrario, la que predomina en el centro y norte peninsular y también en la ciudad de Tingi, en la Mauritania Tingitana, con la que Gozálbez Cravioto pone en relación Baelo. Lo que singulariza a Baelo, además de este hecho, es que en ella es frecuente el desarrollo de la expresión, como ocurre en nuestro caso, y no el recurso a la simple abreviatura. También que en raras ocasiones se menciona al dedicante.

El segundo es el del nombre de la difunta: Iuniae Rufinae ${ }^{7}$, que va en genitivo, aunque también podría estar en dativo. Parece que con el paso del tiempo el significado de genitivo y dativo acabó por ser el mismo y que ambas son más tardías que la construcción en nominativo (Tantimoniaco, 2014: 263 y 296).

El nomen Iunius y su variante femenina Iunia son de los más extendidos en Hispania. Ocupan el noveno lugar de la serie, con 203 menciones recogidas por Abascal (1994). Es relativamente frecuente en la Bética y la Lusitania, tanto en nombres de ingenui como serviles. En la forma Iunius Rufus lo encontramos en Coímbra (CIL II, $5242=$ HEp 22035) y en Carmona (CIL II, $1380=$ HEp 1349), pero no son los únicos. En la propia Baelo existe otra Iunia, Iunia Eleuthera, madre de Q. Pupius Urbicus, que fue duovir de la ciudad en el s. II d. C. (AE 1971, 0172 $=$ AE 1975, $0495=$ EDH, HD011218); una Iunia sin cognomen ni fecha conocidos procede de Cádiz ( $\mathrm{AE}$ 1995, $0783=$ HEp $0260=$ EDH, HD050626) y una Iunia Gaditana esposa de Q. Iulius, datada en 109

7 Se prefiere esta forma a la de Iunia Rufa, que también sería posible, por ser más frecuente en la epigrafía romana. 
d. C., se encontró en Pernik, Bulgaria (aE 1979, $0553=\mathrm{EDH}, \mathrm{HD} 008452)^{8}$.

El cognomen Rufinus/Rufina hace alusión al color rojizo del cabello. En sus versiones masculina y femenina es el quinto más frecuente en Hispania, con 163 testimonios masculinos y 65 femeninos recogidos por Abascal en 1994, con fuerte representación en el s. II d. C. En cambio, el nombre del que derivan, Rufus/Rufa, presenta una marcada diferencia entre géneros, pues frente a 203 masculinos solo se cuentan ocho femeninos. Son escasos en el sur de la península, donde solo se encontraban cinco Rufina y ocho Rufinus, 28 Rufus y ninguna Rufa. Parecen cognomina de origen servil, propios de siervos y libertos, aunque no exclusivos de ellos, y seguramente uno de los típicos Decknamen, nombres indígenas o de raíz púnica camuflados bajo una forma latina (Jiménez Losa, 1997: 188) ${ }^{9}$. Rufina está mucho más extendida que Rufa, por lo que optamos por esta versión. No sabemos si la forma abreviada $R u f$ que encontramos en este epígrafe se debió a una intención expresa o a la escasez de letras disponibles. No hay que olvidar que ya se había tenido que reutilizar una e para la I de Iunia y ahora volverían a encontrar el mismo problema para la I de Rufina.

Los nombres de Iunia Rufa y Iunia Rufina, y los de sus versiones masculinas Iunius Rufus y Iunius Rufinus, son poco frecuentes en la onomástica romana. En el entorno de nuestro epígrafe no se encuentran Iunia Rufa ni Iunia Rufina ni Iunius Rufinus $^{10}$. Solo Iunius Rufus está atestiguado en

8 A título meramente ilustrativo, podemos referir la existencia de una Iunia Rufina en un epígrafe de Saturnia, en Etruria, dedicado también a los Diis Manibus de su esposo C. Didius Vitulus (AE 1977, $0257=$ EDH, HD006774, entre 151 y $300 \mathrm{~d}$. C.).

9 Cf. también Morales, M. (2005): La esclavitud en las colonias romanas de Andalucía. Tesis doctoral presentada en 2005 en la Univ. de Granada, pp. 221-223; disponible en https://digibug.ugr.es/handle/10481/633 (acceso 20/11/2019).

${ }_{10} \mathrm{Al}$ igual que en el caso anterior, encontramos al menos un Lucius Iunius Rufinus Proculianus, tribuno de la legio XIII Gemina, que entre 151 y 170 dedicó una inscripción a Isis y Serapis en Apulum (CIL 03, $07770=$ EDH, HD038518); también un Caius Innius Rufus, procurator del patrimonio
Carmona y Évora (CIL II, 1380 = HEp 1349 y 5242 = HEp 22035, respectivamente).

Las letras de la inscripción, como hemos dicho más arriba, están fundidas en bronce y ancladas mediante espigas a un sillar revestido con dos capas de enlucido, capas que los vástagos de bronce atravesaron para fijarse en la piedra.

Las letras de bronce sobre piedra, sea noble o un simple sillar, es una técnica que se implanta en Roma a principios del s. I d. C. y tiene tiene su principal desarrollo en inscripciones nobles, tanto de pared como de pavimento (Abascal, 2017: 573575). Dos son las técnicas principales. Una consiste en rebajar en el soporte un espacio similar al que ocupan las letras, para que no sobresalgan, y fijarlas al fondo mediante espigas soldadas o fundidas con la propia letra. Otra, fijarlas directamente al fondo por medio de una serie de vástagos similares a los anteriores, de manera que queden en relieve (Stylow y Ventura, 2013: 301). Casi todas las letras de bronce han desaparecido, tanto por el paso del tiempo como por el alto precio del bronce y lo fácil que es fundirlo y reutilizarlo. En estos casos, el texto de la inscripción puede leerse o bien a través de los alvéolos tallados para alojar las letras o bien a través de los orificios abiertos para fijar los vástagos de sujeción (Stylow y Ventura, 2013: 305).

La mayor parte de estas inscripciones corresponden a monumentos representativos importantes y es Hispania, por detrás de Italia, el lugar donde son más frecuentes. La Hispania romana es prácticamente el único lugar en que esta técnica se aplicó también a inscripciones privadas y funerarias (Abascal et al., 2001: 129) ${ }^{11}$.

Este es el caso de la que ahora nos ocupa, una inscripción funeraria que conserva todas sus letras

imperial en Roma, de época antonina ( $\mathrm{AE}$ 1907, $0120=$ EDH, HD023642, y un Marcus Iunius Rufus, prefecto de Egipto entre 94 y 98 (CIL VI, 9752; cIL VI, 33815).

11 Entre estos epígrafes funerarios el más conocido es el del monumento de Fabara (CIL II, 5851 = HEp. 8, $566=$ AE 2000, 777), que ha sido objeto de varios intentos de reconstrucción (Blanco, 1978: 670-673; Beltrán Lloris, 1998: 253-264). Para los de la Hispania Citerior puede verse la recopilación de Stylow y Ventura, 2013. 
y signos de interpunción, sólidamente anclados al sillar y englobados en una capa de estuco de 1,2 $\mathrm{cm}$ de espesor y un enlucido de unos 3-5 mm. Es una técnica muy poco frecuente, cuya existencia ya sospecharon Serrano, Atencia y Rodríguez Oliva (1991-1992: 173-174) al estudiar unas letras y signos de interpunción que conservaban las clavijas y los travesaños en tan buen estado que pensaron que tendrían que haber estado encastrados en un soporte blando, quizás madera, o en el mortero de recubrimiento de una fachada.

En el trabajo de Stylow y Ventura sobre los ejemplos conocidos en la península ibérica, destaca un epígrafe del teatro de Mérida cuyas espigas de anclaje son entre 1,5 y $2 \mathrm{~cm}$ más largas que la profundidad de los orificios en que se iban a anclar. Los autores concluyen que la diferencia tenía que haberse cubierto mediante una capa de enlucido, la misma solución, por tanto, que encontramos en nuestro epígrafe (Stylow y Ventura, 2013: 308, cat. s-34).

\section{Consideraciones finales}

Junto a la información histórica que aportan, el carácter excepcional de los mausoleos viene a ofrecer nuevas potencialidades a la hora de aproximarnos a las élites baelonenses, y en especial a la mujer, al tiempo que suponen un recurso excepcional de cara a la puesta en valor del espacio funerario anexo a la Puerta Sureste o 'Puerta de Carteia'. Por otro lado, la disección estratigráfica que se ha llevado a cabo permite determinar y fijar los momentos de despegue económico y crisis en la ciudad, plasmados en la construcción y decoración marmórea del mausoleo T-32. El cotejo de estos nuevos datos con otros obtenidos en distintos puntos de la ciudad, tales como la factoría de salazones (Arévalo y Bernal, 2007), el macellum (Didierjean et al., 1986) o la recientemente excavada área sureste del foro (Brassous et al., 2017), por citar algunos, amplía la información sobre la crisis del s. III en Baelo y el abandono generalizado o la transformación de muchas estructuras que tuvo lugar a lo largo del s. Iv.
En este sentido, y con reflejo directo en la construcción-uso-abandono-destrucción del mausoleo de Iunia Rufina, de la lectura de las obras de Sillières, entre otros investigadores, se desprende que la ciudad vivió su máximo apogeo a lo largo del s. II (Sillières, 1997: 56; Vaquerizo, 2013). La decoración arquitectónica del mausoleo $\mathrm{T}-32$, con materiales de prestigio entre los que destacan los capiteles corintios, y la escultura se fecharían en ese mismo momento, aunque, como se ha visto, la construcción del cuerpo del mausoleo y del muro perimetral del acotado funerario debió de ser anterior y fecharse durante la segunda mitad del s. I según los materiales. Ello revela que el edificio original sufrió alguna reforma.

Si la decoración arquitectónica, la escultura y la magnífica inscripción con letras de bronce de Iunia Rufina pueden datarse a lo largo del s. II, los niveles de abandono que ya hemos referido se sucedieron prácticamente sin solución de continuidad, en apenas unas décadas. El citado P. Sillières subraya que las ruinas fueron invadiendo la ciudad. Los basureros y los estratos de abandono se generalizaron en la segunda mitad del s. III y a lo largo del IV. La excavación de los patios del macellum es elocuente en este sentido, al aparecer estos rellenados con detritus (Sillières, 1997: 58). De hecho, nuestra intervención ha constatado que, bajo el nivel de escombro procedente del derrumbe de la estructura y que fechamos a lo largo de la segunda mitad del s. Iv, lo que se detecta es un nivel de abandono previo. Los materiales asociados a este estrato pueden adscribirse al s. III y han de ponerse en relación con la situación de crisis documentada en la ciudad.

Si observamos este momento en el resto del entramado baelonense, está bien atestiguado un retroceso urbano y el abandono de edificios públicos desde mediados del s. III. Ya hemos aludido al caso del macellum; otro ejemplo será la cella del Templo c, que igualmente se hundió en este mismo momento para no volver a ser levantada nunca (Sillières, 1997: 58; Bonneville et al., 2000). Todo apunta a que esta fase de crisis y retroceso supuso la desaparición de la figura de los evergetas, que no solo se ocuparon 
de construir los grandes monumentos, sino, sobre todo, de su mantenimiento. En este mismo sentido hemos de interpretar la falta de cuidado y limpieza del interior del acotado funerario del mausoleo T-32.

El saqueo casi sistemático a que se vio sometido el mausoleo T-31 se puede explicar porque por toda la ciudad se documentan nuevas construcciones que desviaron los ejes urbanos y ocuparon espacios públicos. Se trató principalmente de casas, que emplearon para la base de los muros este tipo de sillares expoliados. Estas construcciones se vinculan con la llegada de nueva población desde finales del s. IV o principios del v (Sillières, 1997: 61).

Debido a la visión parcial que tenemos desde la necrópolis, poco podemos argumentar en este sentido, si bien las inhumaciones que van ocupando el área de T-32, y que están en pleno análisis forense en este momento, están atestiguando una presencia de individuos subsaharianos que fueron depositados siguiendo un rito claramente cristiano. La próxima excavación de la zona exterior de los mausoleos, donde son visibles varias tumbas más, enriquecerá sin duda esta hipótesis y quizás ayudará a dotar de contenido la propuesta esgrimida anteriormente que defiende la llegada de una nueva comunidad.

De lo que no cabe duda es del uso funerario de esta zona, de nuevo, tras el terremoto -ya en los ss. V y VI-. La orientación de los nuevos sepulcros, con la cabecera de las tumbas hacia el oeste, permite inferir que se trató de una necrópolis cristiana. Además, la existencia de este tipo de lugares de enterramiento tardíos en torno a los viejos mausoleos altoimperiales es un fenómeno habitual en estas fases. En la propia necrópolis oriental, adosado a un acotado funerario del s. I que se encuentra junto a la playa -Tumba 17, excavada en 2014-, se construyó un sepulcro con mesa de ofrendas (Prados y Jiménez, 2016: 278). Se trata de un hecho bastante frecuente en las necrópolis, y suele relacionarse generalmente con cultos cristianos que fueron identificando los antiguos mausoleos con martyria, y, por ello, las tumbas se van sucediendo alrededor conformando una tumulatio ad sanctos.

Ediciones Universidad de Salamanca / @Q@्త]

\section{Abreviaturas}

$\mathrm{AE}=$ Archivo Epigráfico

AEp = L'Année Épigraphique

$\mathrm{CIL}=$ Corpus Inscriptionum Latinarum.

$\mathrm{EDH}=$ Epigraphische Database Heidelberg, edición digital:

https://edh-www.adw.uni-heidelberg.de/home/

\section{Bibliografía}

Abascal, J. M. (1994): Los nombres personales en las inscripciones latinas de Hispania. Murcia: Univ. de Murcia.

Abascal, J. M. (2017): "Augusto y el eco epigráfico de Munda en Carthago Nova, Saguntum y Tarraco", Gerión, 35, pp. 571-581.

Abascal, J.; Alföldy, G. y Cebrián, R. (2001): “La inscripción con letras de bronce y otros documentos epigráficos del foro de Segobriga", Archivo Español de Arqueología, 74, pp. 117-130.

Arévalo, A. y Bernal, D. (coords.) (2007): Las cetariae de Baelo Claudia. Avance de las investigaciones arqueológicas en el barrio meridional (2000-2004). Cádiz: Junta de Andalucía.

Arévalo, A.; Bernal, D.; Muñoz, A.; García Jiménez, I. y Macías, M. (2006): "El mundo funerario tardorromano en Baelo Claudia: novedades de las intervenciones arqueológicas del yacimiento en la muralla oriental". En VAQUerizo, D. (ed.): Espacios $y$ usos funerarios en la ciudad histórica. Anales de Arqueología Cordobesa, 17 (2). Córdoba, pp. 61-84.

BAEnA, L. (2000): “Tipología y funcionalidad de las esculturas femeninas vestidas de Hispania”. En León P. y Nogales, T. (coords.): Actas III Reunión sobre Escultura romana en Hispania. Madrid: Ministerio de Cultura, pp. 1-23.

BAEnA, L. (2009): "Estatuas togadas y femeninas vestidas”. En León, P. (coord.): El Arte romano de la Bética. La escultura. Sevilla: Focus-Abengoa, pp. 235-274.

Beltrán, J. y LozA, M. L. (2012): “Esculturas romanas de Vlisi (Archidona, Málaga)”, Spal, 21, pp. 39-55.

Beltrán Lloris, F. (1998): "Las inscripciones del 'Mausoleo de Fabara' (Zaragoza)", Caesaraugusta, 74, pp. 253-264.

Bernal, D.; Arévalo, A.; Cantillo, J. J.; García Jiménez, I. y Macías, M. (2015): "Necrópolis tardoantiguas y cristianismo en Baelo Claudia”. En 
Prados, F. y Jiménez, H. (eds.): La muerte en Baelo Claudia. Necrópolis y ritual en el confin del Imperio romano. Cádiz-Alicante: Univ. de Cádiz-Univ. d'Alacant, pp. 125- 136.

Berni, P. y Moros, J. (2012): "Los sellos in planta pedis de las ánforas olearias béticas Dressel 23 (primera mitad s. v d. C.)", Archivo Español de Arqueología, 85, pp. 193-219.

Blanco, A. (1978): "La epigrafía y los monumentos". En Actas $v$ Congreso Español de Estudios Clásicos. Madrid, pp. 669-678.

Bonneville, J.-N.; Dardaine, S. y Le Roux, P. (1988): Belo v. L'épigraphie. Les inscriptions romaines de Baelo Claudia. Série Archéologie, x. Madrid: Casa de Velázquez.

Bonneville, J.-N.; Fincker, M.; Sillières, P.; Dardaine, S. y Labarthe, J. M. (2000): Belo ViI. Le Capitole. Collection de la Casa de Velázquez, 67. Madrid, 2 vols.

Brassous, L.; Deru, X.; Rodríguez, O.; Dananai, A.; Dienst, S.; Doyen, J.-M.; Florent, G.; Gomes, M.; Lemaître, S.; Louvion, C. ; Oueslati, T. y Renard, S. (2017): "Baelo Claudia dans l'Antiquité tardive. L'occupation du secteur sud-est du forum entre les ine et vie siècles". En Brassous, L. y Lemaître, S. (eds.): La ville Antique de Baelo, cent ans après Pierre Paris. Mélanges de la Casa de Velázquez, 47 (1), pp. 167-200.

Didierjean, F.; Ney, C. y Paillet, J.-L. (1986): Belo III. Le macellum. Série Archéologie, v. Madrid: Publications de la Casa de Velázquez.

Gómez Bueno, M. C. (2014): "Dama Romana de Baelo Claudia”, Aljaranda, 77, pp. 13-18.

Gozalbes Cravioto, E. (2002): "Aspectos de la muerte en Tarifa en época romana”, Aljaranda, 45, pp. 4-8.

Hesberg, H. von y Eck, W. (2010): “Die Trasformation des politischen Raumes. Das Bouleterion in Apollonia (Albanien)", Römische Mitteilungen, 116, pp. 257-287.

JimÉNeZ LosA, M. (1997): “Metodología para determinar el colectivo indígena en Augusta Emerita", Veleia, 14, pp. 177-194.

Jiménez Vialás, H. (2017): Carteia y Traducta. Ciudades $y$ territorio en la orilla norte del Estrecho de Gibraltar (siglos VII a. C.-III d. C.). Instrumenta, 57. Barcelona: Univ. de Barcelona.

Keay, S. J. (1984): Late Roman Amphorae in the Western Mediterranean. A typology and economic study: The Catalan evidence. BAR Intern. Ser., 1.136. Oxford: Archaeopress.
Le Roux, P. 2009: "Inscriptions romaines de Belo, 1988-2008", Mélanges de la Casa de Velázquez, 39 (1), pp. 163-174.

LozA, M. L. (2005): "Esculturas romanas de Baelo Claudia". En Preactas de la V Reunión Escultura Romana en Hispania. Murcia: Dirección General de Cultura, pp. 93-97.

LozA, M. L. (2010): "Nuevas esculturas femeninas icónicas de la ciudad romana de Baelo Claudia (Bolonia, Tarifa, Cádiz)". En Abascal, J. M. y Cebrián, R. (eds.): Actas de la vi Reunión sobre Escultura romana en Hispania. Murcia: Tabularium, pp. 119-136.

Menanteau, L.; Vanney, J. R. y Zazo, C. (1983): Belo II: Belo et son environment (Détroit de Gibraltar), Étude physique d'un site antique. Casa de Velázquez. Paris: Éd. Broccard.

Paris, P.; Bonsor, G.; Laumonier, A.; Ricard, R. y De Mergelina, C. (1926): Fouilles de Belo (Bolonia, province de Cadix) (1917-1921), t. II: La nécropole. Bordeaux: Bibliothèque de l'École des Hautes Études Hispaniques.

Pensabene, P. (1973): Scavi di Ostia VII. I Capitelli. Roma: Libreria dello Stato.

Pensabene, P. (2002): "Commitenza edilizia a Ostia tra la fine del i e i primi decenni del inI secolo. Lo studio dei marmi e della decorazione architettonica comi strumento d'indagine", Mélanges de l'École Française de Rome, 114 (1), pp. 181-324.

Prados, F. (2015): "La necrópolis oriental de Baelo Claudia. Paisaje y Arquitectura funerarios". En Prados, F. y Jiménez, H. (eds.): La muerte en Baelo Claudia. Necrópolis y ritual en el confin del Imperio romano. Cádiz-Alicante: Univ. de Cádiz-Univ. d'Alacant, pp. 81-96.

Prados, F.; García Jiménez, I. y Jiménez Vialás, H. (2014): “100 años de arqueología funeraria en el estrecho de Gibraltar: Nuevas investigaciones en la necrópolis de Baelo Claudia (Tarifa, Cádiz)", Saguntum. Papeles del Laboratorio de Arqueología de Valencia, 46, pp. 95-112.

Prados, F. y Jiménez vialás, H. (eds.) (2015): La muerte en Baelo Claudia. Necrópolis y ritual en el confín del Imperio romano. Cádiz-Alicante: Universidad de Cádiz-Universitat d'Alacant.

Prados, F. y Jiménez Vialás, H. (2016): “La materialidad de la muerte en la necrópolis de Baelo Claudia. Ritos y creencias en contexto", Archivo Español de Arqueologia, 89, pp. 273-291. 
Ramallo, S. (ed.) (2004): La decoración arquitectónica de las ciudades romanas de occidente. Murcia: Univ. de Murcia.

Remesal, J. (1979): La necrópolis sureste de Belo. Excavaciones Arqueológicas en Espańa, 104. Madrid.

Remolì, J. A. (2000): Las ánforas tardo-antiguas en Tarraco (Hispania Tarraconensis). Instrumenta, 7, Barcelona: Univ. de Barcelona.

Rodríguez Gutiérrez, O. (2004): "Programas decorativos de época severiana en Itálica". En Ramallo, S. (ed.): La decoración arquitectónica de las ciudades romanas de occidente. Murcia: Universidad de Murcia, pp. 355-377.

Rohmann, J. (1998): Die Kapitellproduktion der römischen Kaiserzeit in Pergamon. Pergamenische Forschungen, 10. Berlin: Deutsches Archäologisches Institut.

Röth, J.; Mathes-Schmidt, M.; García, I.; Rojas, F. J.; Grützner, C.; Silva, P. G. y Reicherter, K. (2015): "The Baelo Claudia tsunami hypothesis: results from a multi-method sediment analysis of late-Roman deposits (Gibraltar Strait, Southern Spain)". En Blumetti, A. M. (ed.): 6th International Inqua Meeting on Paleoseismology, Active Tectonics and Archaeoseismology (19-24 April 2015, Pescina, Fucino Basin, Italy). Miscaellenea, 27. Istituto Nazionale di Geofisica e Vulcanologia. Roma, pp. 418-422.

Serrano, E.; Atencia, R. y Rodríguez Oliva, P. (1991-1992): "Novedades epigráficas en Singilia Barba", Mainake, XIII-XIV, pp. 173-174.

Sillières, P. (1997): Baelo Claudia: una ciudad romana de la Bética. Madrid: Casa de Velázquez-Junta de Andalucía.

Silva, P. G.; Borja, F.; Zazo, C.; Goy, J. L.; Bardají, T.; LuQue, L. De; Lario, J. y Dabrio, C. J. (2005): "Archaeoseismic record at the ancient Roman City of Baelo Claudia (Cádiz, south Spain)", Tectonophysics, 408, pp. 129-146.
Silva, P. G.; Giner, J. L.; Reicherter, K.; RodríguezPascua, M. A.; Grützner, C.; García Jiménez, I.; Carrasco, P.; Bardají, T.; Santos, G.; Roquero, E.; Röth, J.; Perucha, M. A.; Pérez López, R.; Fernández Macarro, B.; Martínez Graña, A.; Goy, J. L. y Zazo, C. (2016): "Los terremotos antiguos del conjunto arqueológico romano de Baelo Claudia (Cádiz, Sur de Espańa): Quince ańos de investigación arqueosismológica”, Estudios Geológicos, 72 (1), pp. e050. https://doi.org/10.3989/ egeol.42284.392

Silva, P. G. y Rodríguez Pascua, M. A. (eds.) (2014): Catálogo de los efectos geológicos de los terremotos en España. Madrid: IGME.

Stiros, S. (2001): "The ad 365 Crete earthquake and possible seismic clustering during the fourth to sixth centuries $\mathrm{AD}$ in the Eastern Mediterranean: a review of historical and archaeological data", Journal of Structural Geology, 23, pp. 545-562.

STYLow, A. U. (1995): "Los inicios de la epigrafía latina en la Bética: el ejemplo de la epigrafía funeraria”. En Beltrán, F. (coord.): Coloquio sobre Roma y el nacimiento de la cultura epigráfica en occidente. Zaragoza: Univ. de Zaragoza, pp. 219-238.

Stylow, A. U. y Ventura, A. (2013): "Las inscripciones con litterae aureae en la Hispania Ulterior (Baetica et Lusitania). Aspectos técnicos". En López VILAR, J. (ed.): ler Congrés Internacional d'Arqueologia $i$ Món Antic. Govern i societat a la Hispània romana. Novetats epigràfiques. Homenatge a Géza Alföldy. Tarragona: Mutua Catalana, pp. 301-339.

Tantimonaco, S. (2017): Dis Manibus. Il culto degli Dei Mani attraverso la documentazione epigrafica. Il caso di studio della Regio x. Venetia et Histria. Arys: Antigüedad: religiones y sociedades. Extra 7, pp. 13-397.

VAQUERIZO, D. (2013): "Topography, monumentalization and funerary customs in urban necropoleis in Baetica", Journal of Roman Archaeology, 26, pp. 209-242. 